\title{
Coupling aerosol surface and bulk chemistry with a kinetic double layer model (K2-SUB): oxidation of oleic acid by ozone
}

\author{
C. Pfrang ${ }^{1,2}$, M. Shiraiwa ${ }^{2}$, and U. Pöschl ${ }^{2}$ \\ ${ }^{1}$ University of Reading, Department of Chemistry, P. O. BOX 224, Whiteknights, Reading RG6 6AD, UK \\ ${ }^{2}$ Max Planck Institute for Chemistry, Biogeochemistry Department, 55128 Mainz, Germany
}

Received: 28 October 2009 - Published in Atmos. Chem. Phys. Discuss.: 15 December 2009

Revised: 12 April 2010 - Accepted: 25 April 2010 - Published: 18 May 2010

\begin{abstract}
We present a kinetic double layer model coupling aerosol surface and bulk chemistry (K2-SUB) based on the PRA framework of gas-particle interactions (Pöschl-RudichAmmann, 2007). K2-SUB is applied to a popular model system of atmospheric heterogeneous chemistry: the interaction of ozone with oleic acid. We show that our modelling approach allows de-convoluting surface and bulk processes, which has been a controversial topic and remains an important challenge for the understanding and description of atmospheric aerosol transformation. In particular, we demonstrate how a detailed treatment of adsorption and reaction at the surface can be coupled to a description of bulk reaction and transport that is consistent with traditional resistor model formulations.
\end{abstract}

From literature data we have derived a consistent set of kinetic parameters that characterise mass transport and chemical reaction of ozone at the surface and in the bulk of oleic acid droplets. Due to the wide range of rate coefficients reported from different experimental studies, the exact proportions between surface and bulk reaction rates remain uncertain. Nevertheless, the model results suggest an important role of chemical reaction in the bulk and an approximate upper limit of $\sim 10^{-11} \mathrm{~cm}^{2} \mathrm{~s}^{-1}$ for the surface reaction rate coefficient. Sensitivity studies show that the surface accommodation coefficient of the gas-phase reactant has a strong non-linear influence on both surface and bulk chemical reactions. We suggest that K2-SUB may be used to design, interpret and analyse future experiments for better discrimination

Correspondence to: C. Pfrang (c.pfrang@reading.ac.uk) between surface and bulk processes in the oleic acid-ozone system as well as in other heterogeneous reaction systems of atmospheric relevance.

\section{Introduction}

Atmospheric aerosols are highly variable components of the Earth system that have a substantial impact on the hydrological cycle and climate (Rosenfeld, 2000; Charlson et al., 2001; Ramanathan et al., 2001; Breon et al., 2002; Penner et al., 2004, Andreae et al., 2004; Pöschl, 2005; Fuzzi et al., 2006; Bergstrom et al., 2007, Choularton et al., 2008; Andreae and Rosenfeld, 2008). Thus, full understanding of the properties and transformation of aerosol particles is of key importance for atmospheric science.

The oxidation of organic substances in the atmosphere is predominantly initiated by hydroxyl radicals $(\mathrm{OH})$, nitrate radicals $\left(\mathrm{NO}_{3}\right)$ and ozone $\left(\mathrm{O}_{3}\right)$ (Wayne, 2000). While atmospheric lifetimes of volatile organic compounds are largely determined by the rate coefficients of the chemical reactions with $\mathrm{OH}, \mathrm{NO}_{3}$, and $\mathrm{O}_{3}$ (e.g. King et al., 1999; Pfrang et al., 2006a, b, 2007 and 2008), mass transport parameters are important additional factors for organic aerosol components. Chemical reactions can occur at the surface and in the bulk of aerosol particles, and the rates and relative proportions of surface and bulk reactions are hardly known.

Experimental studies are often rationalised with traditional "resistor" modelling formulations (e.g. Worsnop et al., 2002; Smith et al., 2002; Hearn et al., 2005; Knopf et al., 2005; Grimm et al., 2006; Gonzalez-Labrada et al., 2007; King et al., 2008, 2009; Gross et al., 2009), but the applicability and

Published by Copernicus Publications on behalf of the European Geosciences Union. 
usefulness of this approach is limited with regard to multicomponent systems and transient conditions.

To overcome these limitations, Pöschl et al. (2007) have developed a kinetic flux modelling approach (PRA framework) which enables a consistent and flexible treatment of aerosol chemistry and gas-particle interactions, including mass transport and chemical reactions in multiphase and multi-component systems. Springmann et al. (2009) demonstrated the applicability and usefulness of the PRA framework in an urban plume box model of the degradation of benzo[a]pyrene on soot by ozone and nitrogen dioxide. Shiraiwa et al. (2009) showed that the PRA approach can be efficiently applied to other polycyclic aromatic hydrocarbons (PAHs) and photo-oxidants $\left(\mathrm{O}_{3}, \mathrm{NO}_{2}, \mathrm{OH}\right.$ and $\left.\mathrm{NO}_{3}\right)$ with multiple types of parallel and sequential surface reactions using a kinetic double-layer model (K2-SURF).

De-convolution of competing surface and bulk processes is essential for a detailed understanding of aerosol transformation and ageing. A well studied model system for atmospherically relevant heterogeneous reactions is the interaction of oleic acid with atmospheric trace gases, in particular $\mathrm{O}_{3}$ (e.g. Smith et al., 2002; Hearn et al., 2005; Grimm et al., 2006; Reynolds et al., 2006; Hung and Ariya, 2007; Gonzalez-Labrada et al., 2007; Hearn and Smith, 2007; Lee and Chan, 2007; Voss et al., 2007; Zahardis and Petrucci, 2007; King et al., 2008, 2009, 2010; Vesna et al., 2008a, b, 2009; Sage et al., 2009; Last et al., 2009).

Despite intense research efforts to fully understand the oleic acid-ozone system, there remain large uncertainties documented in the wide range of reported uptake coefficients varying by nearly four orders of magnitude (see Table 1). There is also controversy on the relative importance of bulk and surface processes (compare e.g. Hearn et al., 2005). Here we demonstrate how the competing surface and bulk processes can be de-convoluted with a kinetic double layer model coupling surface and bulk chemistry (K2-SUB).

\section{Modelling approach}

Our kinetic double-layer model coupling aerosol surface and bulk chemistry (K2-SUB) builds on the PRA framework (Pöschl et al., 2007) and uses the same terminology. For definitions and detailed explanation of symbols see Appendices A and B as well as Pöschl et al. (2007). The mass balance for a reactive liquid-phase species Y (e.g. oleic acid) can be expressed as

$$
\frac{d N_{\mathrm{y}}}{d t}=\frac{d N_{\mathrm{y}, \mathrm{ss}}}{d t}+\frac{d N_{\mathrm{y}, \mathrm{b}}}{d t}=\frac{d[\mathrm{Y}]_{\mathrm{ss}}}{d t} \times A_{\mathrm{ss}}+\frac{d[\mathrm{Y}]_{\mathrm{b}}}{d t} \times V_{\mathrm{b}}
$$

with $N_{\mathrm{y}}$ being the total number of Y molecules; $N_{\mathrm{y}, \mathrm{ss}}$ and $N_{\mathrm{y}, \mathrm{b}}$ are the numbers of molecules in surface and bulk; $[\mathrm{Y}]_{\mathrm{ss}}$ and $[\mathrm{Y}]_{\mathrm{b}}$ the surface and bulk concentrations of $\mathrm{Y}$; and $A_{\mathrm{ss}}$ and $V_{\mathrm{b}}$ being surface area and bulk volume of the particle.
Expressed in fluxes:

$\frac{d[\mathrm{Y}]_{\mathrm{ss}}}{d t}=J_{\mathrm{b}, \mathrm{ss}, \mathrm{Y}}-J_{\mathrm{ss}, \mathrm{b}, \mathrm{Y}}-L_{\mathrm{ss}, \mathrm{Y}}$

and

$\frac{d[\mathrm{Y}]_{\mathrm{b}}}{d t}=\left(J_{\mathrm{ss}, \mathrm{b}, \mathrm{Y}}-J_{\mathrm{b}, \mathrm{ss}, \mathrm{Y}}\right) \times \frac{A_{\mathrm{ss}}}{V_{\mathrm{b}}}+L_{\mathrm{b}, \mathrm{Y}}$

with the terms $L_{\mathrm{ss}, \mathrm{Y}}$ and $L_{\mathrm{b}, \mathrm{Y}}$ representing the chemical loss of $\mathrm{Y}$ in surface and bulk; $J_{\mathrm{b}, \mathrm{ss}, \mathrm{Y}}=k_{\mathrm{b}, \mathrm{ss}, \mathrm{Y}} \times[\mathrm{Y}]_{\mathrm{b}}$ and $J_{\mathrm{ss}, \mathrm{b}, \mathrm{Y}}=k_{\mathrm{ss}, \mathrm{b}, \mathrm{Y}} \times[\mathrm{Y}]_{\mathrm{ss}}$ are the fluxes of bulk-surface and surface-bulk mass transport, respectively.

The uptake coefficient of a gas-phase species $\mathrm{X}\left(\right.$ e.g. $\left.\mathrm{O}_{3}\right)$, $\gamma_{\mathrm{x}}$, is defined by

$\gamma_{x}=\frac{J_{\mathrm{ads}, \mathrm{X}}-J_{\mathrm{des}, \mathrm{X}}}{J_{\mathrm{coll}, \mathrm{X}}}$

where $J_{\mathrm{ads}, \mathrm{X}}$ and $J_{\mathrm{des}, \mathrm{X}}$ are fluxes of adsorption and desorption of $\mathrm{X}$ and $J_{\text {coll, } \mathrm{X}}$ corresponds to the gas kinetic flux of $\mathrm{X}$ molecules colliding with the surface

$J_{\mathrm{coll}, \mathrm{X}}=\frac{[\mathrm{X}]_{\mathrm{gs}} \omega_{\mathrm{X}}}{4}$.

$[\mathrm{X}]_{\mathrm{gs}}$ is the gas phase concentration of $\mathrm{X}$ near the surface. For low values of $\gamma_{\mathrm{X}}$ and small particles (high Knudsen number, $K n_{\mathrm{x}}=\lambda_{\mathrm{x}} r_{\mathrm{p}}^{-1}$ with $\lambda_{\mathrm{x}}$ corresponding to the mean free path of $\mathrm{X}$ and $r_{\mathrm{p}}$ being the particle radius), [X $]_{\mathrm{gs}}$ equals the average gas phase concentration $[\mathrm{X}]_{\mathrm{g}}$. In case of high uptake and large particles, the rate of gas uptake can be limited by gasphase diffusion. Differences between $[\mathrm{X}]_{\mathrm{gs}}$ and $[\mathrm{X}]_{\mathrm{g}}$ can be described by a diffusion correction factor $\left(C_{\mathrm{g}, \mathrm{X}}\right)$ as detailed by Pöschl et al. (2007). Figure 1 illustrates the structure of the kinetic double-layer model (K2-SUB) presented here.

Assuming steady-state we obtain the following mass balance equation for $\mathrm{X}$ at the surface:

$J_{\mathrm{ads}, \mathrm{X}}-J_{\mathrm{des}, \mathrm{X}}-J_{\mathrm{s}, \mathrm{b}, \mathrm{X}}+J_{\mathrm{b}, \mathrm{s}, \mathrm{X}}-L_{\mathrm{s}, \mathrm{X}}=0$

Assuming near-planar geometry of the surface, the flux of chemical loss of $\mathrm{X}$ in the sorption layer, $L_{\mathrm{s}, \mathrm{X}}$, can be equated to the chemical loss of $\mathrm{Y}$ in the surface, $L_{\mathrm{ss}, \mathrm{Y}}$ :

$L_{\mathrm{s}, \mathrm{X}}=k_{\mathrm{SLR}, \mathrm{X}, \mathrm{Y}}[\mathrm{X}]_{\mathrm{s}}[\mathrm{Y}]_{\mathrm{ss}}=k_{\mathrm{s}, \mathrm{X}} \times[\mathrm{X}]_{\mathrm{S}}=L_{\mathrm{ss}, \mathrm{Y}}$.

$k_{\mathrm{SLR}, \mathrm{X}, \mathrm{Y}}$ is the second-order rate coefficient for the surface layer reactions between $\mathrm{X}$ and $\mathrm{Y}$ and $k_{\mathrm{s}, \mathrm{X}}$ is the corresponding pseudo-first order reaction rate coefficient. For very small particles where the surface curvature is strong on molecular scales, Eq. (7) could be corrected by the ratio of sorption layer and quasi-static surface areas. The concentration of $\mathrm{X}$ at the surface, $[\mathrm{X}]_{\mathrm{s}}$, is given by (terms are defined in Appendices A and B):

$[\mathrm{X}]_{\mathrm{s}}=[\mathrm{SS}]_{\mathrm{ss}} \frac{K_{\mathrm{ads}, \mathrm{X}}^{\prime}[\mathrm{X}]_{\mathrm{gs}}}{1+K_{\mathrm{ads}, \mathrm{X}}^{\prime}[\mathrm{X}]_{\mathrm{gs}}}$. 
Table 1. Experimental conditions and results of laboratory studies investigating the reactive uptake of ozone by oleic acid (compare Tables 1 and 2 in Zahardis and Petrucci, 2007; Gonzalez-Labrada et al., 2007 and King et al., 2009).

\begin{tabular}{|c|c|c|c|c|c|c|}
\hline $\begin{array}{l}\text { Method/ } \\
\text { detection }^{\text {a }}\end{array}$ & $\begin{array}{l}r_{\mathrm{p}} / \\
\mu \mathrm{m}\end{array}$ & $\begin{array}{l}{\left[\mathrm{O}_{3}\right] /} \\
\mathrm{cm}^{-3}\end{array}$ & $\begin{array}{l}\text { Timescale/ } \\
\text { s }\end{array}$ & $\begin{array}{l}k_{\mathrm{SLR}, \mathrm{X}, \mathrm{Y}} / \\
\mathrm{cm}^{2} \mathrm{~s}^{-1}\end{array}$ & $\gamma_{\mathrm{x}}$ & Reference \\
\hline AFT/ CIMS & $0.3-0.5$ & $2.5 \times 10^{15}$ & 4 & & $(7.5 \pm 1.2) \times 10^{-4}$ & $\begin{array}{l}\text { Hearn and Smith } \\
(2004)\end{array}$ \\
\hline AFT/ AMS & $0.1-0.3$ & $2.5 \times 10^{14}$ & 7 & & $(1.6 \pm 0.2) \times 10^{-3}$ & Morris et al. (2002) \\
\hline $\begin{array}{l}\text { AFT/ Single parti- } \\
\text { cle MS }\end{array}$ & $0.7-2.5$ & $3.4 \times 10^{15}$ & 8 & & $\begin{array}{l}(0.99 \pm 0.09)- \\
(7.3 \pm 1.5) \times 10^{-3^{b}} \\
(5.8-9.8) \times 10^{-3^{c}}\end{array}$ & Smith et al. (2002) \\
\hline AFT/ CIMS & $0.3-0.6$ & $2.5-25 \times 10^{14}$ & 4 & & $\begin{array}{l}(1.38 \pm 0.06) \times 10^{-3} \\
(8.8 \pm 0.5) \times 10^{-4^{d}}\end{array}$ & Hearn et al. (2005) \\
\hline EC/ TDPBMS & 0.2 & $7 \times 10^{13}$ & $\sim 15$ & & $(6.1 \pm 5) \times 10^{-4}$ & Ziemann (2005) \\
\hline AFT/ AMS & $1-15$ & $2.5 \times 10^{14}$ & & & $(1.25 \pm 0.2) \times 10^{-3}$ & Katrib et al. (2005) \\
\hline CFT/ CIMS $\left(\mathrm{O}_{3}^{-}\right)$ & N/A & $2-4 \times 10^{12}$ & & & $\begin{array}{l}(0.64 \pm 0.05) \times 10^{-4^{\mathrm{e}}} \\
(7.9 \pm 0.3) \times 10^{-4^{\mathrm{f}}}\end{array}$ & Knopf et al. (2005) \\
\hline CFT/ CIMS $\left(\mathrm{O}_{3}^{-}\right)$ & 500 & $1.0 \times 10^{14}$ & 0.1 & & $\begin{array}{l}(5.2 \pm 0.1) \times 10^{-5^{\mathrm{e}}} \\
(8.3 \pm 0.02) \times 10^{-4^{\mathrm{f}}}\end{array}$ & $\begin{array}{l}\text { Moise and Rudich } \\
\text { (2002) }\end{array}$ \\
\hline $\mathrm{CFT} / \mathrm{CIMS}\left(\mathrm{O}_{3}^{-}\right)$ & 25 & $10^{11}-10^{12}$ & $>0.1$ & & $(8.0 \pm 1.0) \times 10^{-4}$ & $\begin{array}{l}\text { Thornberry and } \\
\text { Abbatt (2004) }\end{array}$ \\
\hline $\begin{array}{l}\text { Monolayer on pen- } \\
\text { dant drop/ ST }\end{array}$ & N/A & $7-615 \times 10^{12}$ & $\sim 500$ & $4.9 \times 10^{-11}$ & $(2.6 \pm 0.1) \times 10^{-6}$ & $\begin{array}{l}\text { Gonzalez-Labrada } \\
\text { et al., } 2007\end{array}$ \\
\hline $\begin{array}{l}\text { Deuterated mono- } \\
\text { layer on Langmuir } \\
\text { trough/ NR }\end{array}$ & N/A & $4.2-12 \times 10^{12}$ & $\sim 6000$ & $\begin{array}{l}(7.3 \pm 0.9) \times 10^{-11} \text { and } \\
(2.1 \pm 2.7) \times 10^{-12} \mathrm{~g}\end{array}$ & $\sim 4 \times 10^{-6}$ & King et al., 2009 \\
\hline
\end{tabular}

a AFT: aerosol flow tube; CIMS: chemical ionisation mass spectrometry; CFT: coated flow tube; AMS: aerosol mass spectrometry; EC: environmental chamber; TDPBMS: thermal desorption particle beam mass spectrometry; MS: mass spectrometry; ST: surface tension measurement; NR: neutron reflectometry.

$\mathrm{b}$ This corresponds to a radii range of monodisperse particles respectively from $2.45 \mu \mathrm{m}$ to $680 \mathrm{~nm}$ with other values for different diameter particles given in the original work.

$\mathrm{c}$ These are the corrected values when accounting for the diffusion of oleic acid; see original work for more details.

$\mathrm{d}$ This is a corrected value accounting for oleic acid loss via secondary chemistry; see the original work for more details.

${ }^{\mathrm{e}}$ This value is for solid-phase oleic acid; see the original work for more details.

$\mathrm{f}$ This value is liquid-phase oleic acid; see the original work for more details.

$\mathrm{g}$ Two branches have been reported with the the dominating branch (branching ratio 0.86) being the faster reaction which leads to formation of surface active products (see King et al., 2009 for more details).

Under steady-state conditions, the reacto-diffusive flux of $\mathrm{X}$ in the particle bulk $\left(J_{\mathrm{b}, \mathrm{rd}, \mathrm{X}}\right)$ can be related to the flux of bulksurface and surface-bulk transfer of $\mathrm{X}$ in the sorption layer $\left(J_{\mathrm{b}, \mathrm{s}, \mathrm{X}}\right.$ and $\left.J_{\mathrm{s}, \mathrm{b}, \mathrm{X}}\right)$ by the following equation

$J_{\mathrm{b}, \mathrm{rd}, \mathrm{X}}=J_{\mathrm{s}, \mathrm{b}, \mathrm{X}}-J_{\mathrm{b}, \mathrm{s}, \mathrm{X}}$.

$J_{\mathrm{b}, \mathrm{rd}, \mathrm{X}}$ can be re-written as

$J_{\mathrm{b}, \mathrm{rd}, \mathrm{X}}=C_{\mathrm{b}, \mathrm{rd}, \mathrm{X}} \sqrt{k_{\mathrm{b}, \mathrm{X}} D_{\mathrm{b}, \mathrm{X}}}[\mathrm{X}]_{\mathrm{bs}}$.

Provided that the interfacial mass transfer proceeds faster than the chemical loss of $\mathrm{X}$, the near-surface bulk concentration $[\mathrm{X}]_{\mathrm{bs}}$ can be approximated by

$[\mathrm{X}]_{\mathrm{bs}}=K_{\mathrm{sol}, \mathrm{cp}, \mathrm{X}} R T[\mathrm{X}]_{\mathrm{gs}}$.

The pseudo-first order loss rate coefficient $k_{\mathrm{b}, \mathrm{X}}$ is given by

$k_{\mathrm{b}, \mathrm{X}}=k_{\mathrm{BR}, \mathrm{X}, \mathrm{Y}} \times[\mathrm{Y}]_{\mathrm{b}}$ with $k_{\mathrm{BR}, \mathrm{X}, \mathrm{Y}}$ corresponding to the second-order bulk reaction rate coefficient (the other parameters from Eq. (10) are defined in Appendices A and B). $J_{\mathrm{b}, \mathrm{rd}, \mathrm{X}}$ thus represents both diffusion and reactive loss of $\mathrm{X}$ in the particle bulk.

Assuming that the chemical loss of $X$ equals the chemical loss of Y (stoichiometric coefficients of unity) we can write

$L_{\mathrm{b}, \mathrm{Y}}=J_{\mathrm{b}, \mathrm{rd}, \mathrm{X}} \times \frac{A_{\mathrm{ss}}}{V_{\mathrm{b}}}$.

Note that Eq. (13) could be flexibly modified to account for stoichiometric coefficients deviating from unity. Recently, Sage et al. (2009) suggested that the stoichiometric ratio between oleic acid and ozone can vary and might be as high as 3.75 under certain conditions. Nevertheless, the uncertainties in reaction stoichiometry appear to be lower than the uncertainties of reaction rate coefficients as discussed 


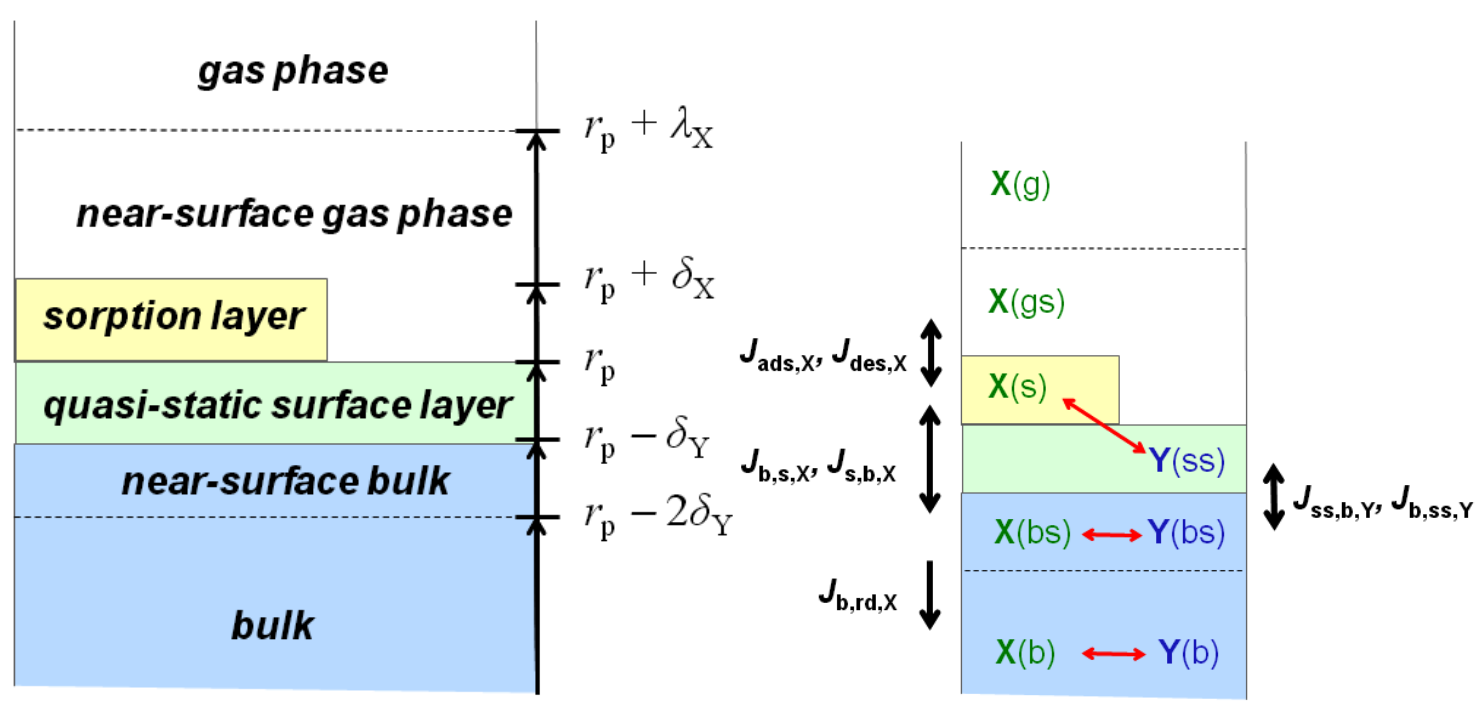

Fig. 1. Kinetic double-layer surface model (K2-SUB): (a) model compartments and distances from the particle centre; (b) model species, transport fluxes (black arrows) and chemical reactions (red arrows). $r_{\mathrm{p}}$ is the particle radius, $\delta_{\mathrm{X}}$ and $\delta_{\mathrm{Y}}$ are the effective molecular diameters and molecular layer thicknesses for volatile species $\mathrm{X}$ and non-volatile species $\mathrm{Y}$, respectively; $\lambda_{\mathrm{X}}$ is the mean free path of $\mathrm{X}$ in the gas phase.

above (Sect. 1, Table 1). Thus, we do not explore this aspect in the present study.

By inserting Eqs. (7), (10) and (13) into Eqs. (1), (2) and (3) we obtain

$$
\begin{aligned}
\frac{d N_{\mathrm{y}, \mathrm{ss}}}{d t} & =\frac{d[\mathrm{Y}]_{\mathrm{ss}}}{d t} \times A_{\mathrm{ss}}=\left\{k_{\mathrm{b}, \mathrm{ss}, \mathrm{Y}} \times[\mathrm{Y}]_{\mathrm{b}}-k_{\mathrm{ss}, \mathrm{b}, \mathrm{Y}} \times[\mathrm{Y}]_{\mathrm{ss}}\right. \\
& \left.-k_{\mathrm{SLR}, \mathrm{X}, \mathrm{Y}}[\mathrm{X}]_{\mathrm{s}}[\mathrm{Y}]_{\mathrm{ss}}\right\} \times A_{\mathrm{ss}}
\end{aligned}
$$

and

$$
\begin{aligned}
\frac{d N_{\mathrm{y}, \mathrm{b}}}{d t} & =\frac{d[\mathrm{Y}]_{\mathrm{b}}}{d t} \times V_{\mathrm{b}}=\left\{k_{\mathrm{ss}, \mathrm{b}, \mathrm{Y}} \times[\mathrm{Y}]_{\mathrm{ss}}-k_{\mathrm{b}, \mathrm{ss}, \mathrm{Y}} \times[\mathrm{Y}]_{\mathrm{b}}\right. \\
& \left.-C_{\mathrm{b}, \mathrm{rd}, \mathrm{X}} \sqrt{k_{\mathrm{b}, \mathrm{X}} D_{\mathrm{b}, \mathrm{X}}}[\mathrm{X}]_{\mathrm{bs}}\right\} \times A_{\mathrm{ss}} .
\end{aligned}
$$

Thus

$$
\begin{aligned}
\frac{d[\mathrm{Y}]_{\mathrm{b}}}{d t} & =\left\{k_{\mathrm{ss}, \mathrm{b}, \mathrm{Y}} \times[\mathrm{Y}]_{\mathrm{ss}}-k_{\mathrm{b}, \mathrm{ss}, \mathrm{Y}} \times[\mathrm{Y}]_{\mathrm{b}}\right. \\
& \left.-C_{\mathrm{b}, \mathrm{rd}, \mathrm{X}} \sqrt{k_{\mathrm{b}, \mathrm{X}} D_{\mathrm{b}, \mathrm{X}}}[\mathrm{X}]_{\mathrm{bs}}\right\} \times \frac{A_{\mathrm{ss}}}{V_{\mathrm{b}}},
\end{aligned}
$$

and for a spherical particle with a radius much larger than the effective molecular diameter of $\mathrm{Y}\left(r_{\mathrm{p}} \gg \delta_{\mathrm{Y}}\right)$

$$
\begin{aligned}
\frac{d[\mathrm{Y}]_{\mathrm{b}}}{d t} & =\left\{k_{\mathrm{ss}, \mathrm{b}, \mathrm{Y}} \times[\mathrm{Y}]_{\mathrm{ss}}-k_{\mathrm{b}, \mathrm{ss}, \mathrm{Y}} \times[\mathrm{Y}]_{\mathrm{b}}\right. \\
& \left.-C_{\mathrm{b}, \mathrm{rd}, \mathrm{X}} \sqrt{k_{\mathrm{b}, \mathrm{X}} D_{\mathrm{b}, \mathrm{X}}}[\mathrm{X}]_{\mathrm{bs}}\right\} \times \frac{3}{r_{p}}
\end{aligned}
$$

Under steady-state conditions, using Eqs. (4), (6) and (9) the uptake coefficient can be described as
$\gamma_{\mathrm{x}}=\frac{J_{\mathrm{b}, \mathrm{rd}, \mathrm{X}}+L_{\mathrm{s}, \mathrm{X}}}{J_{\mathrm{coll}, \mathrm{X}}}$.

This expression can be re-formulated in the popular resistor model approach (compare Pöschl et al., 2007; Eqs. 105-124) as sum of resistance terms

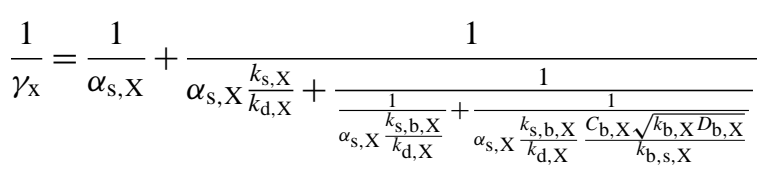

or by inserting inverse resistance (conductance) terms

$$
\frac{1}{\gamma_{\mathrm{x}}}=\frac{1}{\alpha_{\mathrm{s}, \mathrm{X}}}+\frac{1}{\Gamma_{\mathrm{s}, \mathrm{X}}+\frac{1}{\frac{1}{\Gamma_{\mathrm{s}, \mathrm{b}, \mathrm{X}}}+\frac{1}{\Gamma_{\mathrm{b}, \mathrm{X}}}}}
$$

with conductance terms for surface reaction of X,

$\Gamma_{\mathrm{s}, \mathrm{X}}=\frac{4 k_{\mathrm{a}, \mathrm{X}} k_{\mathrm{s}, \mathrm{X}}}{k_{\mathrm{d}, \mathrm{X}} \omega_{\mathrm{X}}}$,

for surface-bulk transfer of $\mathrm{X}$

$\Gamma_{\mathrm{s}, \mathrm{b}, \mathrm{X}}=\alpha_{\mathrm{s}, \mathrm{X}} \frac{k_{\mathrm{s}, \mathrm{b}, \mathrm{X}}}{k_{\mathrm{d}, \mathrm{X}}}$,

and for particle bulk diffusion and reaction of $\mathrm{X}$

$\Gamma_{\mathrm{b}, \mathrm{X}}=\frac{4}{\omega_{x}} K_{\mathrm{sol,cp}, \mathrm{X}} R T C_{\mathrm{b}, \mathrm{rd}, \mathrm{X}} \sqrt{k_{\mathrm{b}, \mathrm{X}} D_{\mathrm{b}, \mathrm{X}}}$.

Our modelling approach is designed to be compatible with resistor-model formulations (e.g. Worsnop et al., 2002; Smith et al., 2002; King et al., 2008, 2009), as derived in 
detail in Appendix C. Please note that the advantage of the $\mathrm{K} 2-\mathrm{SUB}$ approach is that we are not limited to special cases, i.e. we can describe any combination of surface and bulk reactions and transport at any reactivity ratio. K2-SUB provides a general set of equations that describe all physicochemical processes involved. It enables free variation of all relevant parameters in particular mass transfer and reaction rate coefficients. It thus can describe limiting cases as well as any state in between depending on the investigated reaction systems, conditions and rate parameters. The added flexibility compared to previous approaches also facilitates description of Langmuir-Hinshelwood- and Eley-Rideal-type reaction mechanisms.

\section{Derivation of kinetic parameters for the oxidation of oleic acid particles by ozone}

In this study we have focused on the simulation of experimental data from Ziemann (2005), who reported timeresolved concentration data of oleic acid in fine droplets $\left(r_{\mathrm{p}}=0.2 \mu \mathrm{m}\right)$ interacting with ozone at a fixed gas-phase concentration level $\left([\mathrm{X}]_{\mathrm{gs}}=6.95 \times 10^{13} \mathrm{~cm}^{-3}\right.$ corresponding to $2.8 \mathrm{ppm}$ ). Unfortunately, many other studies have reported changes in concentration only as a function of ozone exposure (product of ozone concentration and time), which is less suitable for detailed process modelling. For consistent description and comparison of surface, bulk and total amounts of oleic acid in the investigated particles, we have multiplied the volume concentrations reported by Ziemann (2005) with the particle volume $\left(V_{\mathrm{p}}=4 / 3 \pi r_{\mathrm{p}}^{3}\right)$ to obtain the absolute number of molecules.

For the initial concentration of pure oleic acid we took $[\mathrm{Y}]_{\mathrm{b}, 0}=1.21 \times 10^{21} \mathrm{~cm}^{-3}$ corresponding to $3.15 \mathrm{~mol} \mathrm{~L}^{-1}$ as reported by Ziemann (2005). From the concentration of the pure substance we derived an approximate value for the effective molecular diameter of oleic acid, $\delta_{\mathrm{Y}}$ :

$[\mathrm{Y}]_{\mathrm{b}, 0} \approx \frac{1}{\delta_{\mathrm{Y}}^{3}}$.

From $\delta_{\mathrm{Y}} \approx 0.8 \mathrm{~nm}$ we obtained an approximate value for the effective molecular cross-section $\sigma_{\mathrm{y}} \approx \delta_{\mathrm{Y}}^{2} \approx 0.064 \mathrm{~nm}^{2}$. The initial surface concentration of oleic acid ([Y $\left.]_{\mathrm{ss}, 0}\right)$ was obtained from the relation

$$
[\mathrm{Y}]_{\mathrm{ss}, 0}=\delta_{\mathrm{Y}} \times[\mathrm{Y}]_{\mathrm{b}, 0} \text {. }
$$

Values for $k_{\mathrm{b}, \mathrm{ss}, \mathrm{Y}}$ and $k_{\mathrm{ss}, \mathrm{b}, \mathrm{Y}}$ are derived by considering the average distance travelled by molecules diffusing in one direction (Atkins, 1998):

$$
\sqrt{x^{2}}=\sqrt{\frac{4 D_{\mathrm{b}} t}{\pi}}
$$

with $x$ corresponding to a distance the molecule needs to travel (this equals $\delta_{\mathrm{Y}}$, in our case $0.8 \mathrm{~nm}$ ) and $D_{\mathrm{b}}$ being the diffusion coefficient (for oleic acid $D_{\mathrm{b}, \mathrm{Y}}$ is assumed to be
$10^{-10} \mathrm{~cm}^{2} \mathrm{~s}^{-1}$; this corresponds to the lowest value assumed by Smith et al. (2003) when testing possible effects of slow diffusion in pure oleic acid droplets). For a droplet of $200 \mathrm{~nm}$ there is no oleic acid concentration gradient to be expected in the droplet since the small droplets can be assumed to be well mixed (Smith et al., 2002). For larger droplets a diffusion correction has been suggested (Smith et al., 2003), and this aspect is further explored in a follow-up study (Shiraiwa et al., 2010). An oleic acid molecule would take approximately $50 \mu$ s to travel the distance of $\delta_{\mathrm{Y}}$, so that we obtain a "transport velocity" $\left(k_{\mathrm{b}, \mathrm{ss}, \mathrm{Y}}\right)$ of $1.6 \times 10^{-3} \mathrm{~cm} \mathrm{~s}^{-1}$. This transport velocity can be related to $k_{\mathrm{ss}, \mathrm{b}, \mathrm{Y}}$ by

$k_{\mathrm{b}, \mathrm{ss}, \mathrm{Y}} \times[\mathrm{Y}]_{\mathrm{b}, \max }=k_{\mathrm{ss}, \mathrm{b}, \mathrm{Y}} \times[\mathrm{Y}]_{\mathrm{ss}, \max }$.

The surface concentration is assumed to be limited by the number of surface sites with

$[\mathrm{Y}]_{\mathrm{ss}, \max }=\frac{1}{\delta_{\mathrm{Y}}^{2}}=1.56 \times 10^{14} \mathrm{~cm}^{-2}$

and

$[\mathrm{Y}]_{\mathrm{b}, \max }=\frac{1}{\delta_{\mathrm{Y}}^{3}}=1.95 \times 10^{21} \mathrm{~cm}^{-3}$.

We thus obtain a value for $k_{\mathrm{ss}, \mathrm{b}, \mathrm{Y}}$ of $1.99 \times 10^{4} \mathrm{~s}^{-1}$.

The same line of thought presented for the oleic acid transport velocity $\left(k_{\mathrm{b}, \mathrm{ss}, \mathrm{Y}}\right)$ was followed to derive the transport velocity for ozone $\left(k_{\mathrm{b}, \mathrm{s}, \mathrm{X}}\right)$. Using a diffusion coefficient for ozone $\left(D_{\mathrm{b}, \mathrm{X}}\right)$ in organic solvents of $10^{-5} \mathrm{~cm}^{2} \mathrm{~s}^{-1}$ (Smith et al., 2002, 2003) and $\delta_{\mathrm{X}}$ for ozone of $0.4 \mathrm{~nm}$ (derived from Eq. (28) with a value for surface sites for ozone of $5.7 \times 10^{14} \mathrm{~cm}^{-2}$ reported by Pöschl et al., 2001; compare also a computational study by Vieceli et al., 2004), we obtain from Eq. (26) that $k_{\mathrm{b}, \mathrm{s}, \mathrm{X}}$ is $318 \mathrm{~cm} \mathrm{~s}^{-1}$.

$k_{\mathrm{s}, \mathrm{b}, \mathrm{X}}$ however can be expected to be substantially different from $k_{\mathrm{ss}, \mathrm{b}, \mathrm{Y}}$. As opposed to $k_{\mathrm{b}, \mathrm{s}, \mathrm{X}}, k_{\mathrm{b}, \mathrm{ss}, \mathrm{Y}}$ and $k_{\mathrm{ss}, \mathrm{b}, \mathrm{Y}}$, $k_{\mathrm{s}, \mathrm{b}, \mathrm{X}}$ is not isotropic and the ozone molecules will experience forces significantly different from those experienced by the oleic acid molecules. We thus derived $k_{\mathrm{s}, \mathrm{b}, \mathrm{X}}$ by fitting the value of $K_{\mathrm{sol}, \mathrm{cp}, \mathrm{X}}$ to match the literature value of Henry's law coefficient $\left(H_{\mathrm{cp}, \mathrm{X}}=4.8 \times 10^{-4} \mathrm{~mol} \mathrm{~cm}^{-3} \mathrm{~atm}^{-1}\right.$; e.g. Smith et al., 2002; King et al., 2009). The two other parameters affecting $K_{\mathrm{sol}, \mathrm{cp}, \mathrm{X}}$ in our treatment have been varied within the ranges $k_{\mathrm{d}, \mathrm{X}}=1-10^{3} \mathrm{~s}^{-1}$ and $\alpha_{\mathrm{s}, 0, \mathrm{X}}=4 \times 10^{-4}$ 1 (compare experimental values summarised in Shiraiwa et al., 2009: $k_{\mathrm{d}, \mathrm{X}}=0.1-10^{2} \mathrm{~s}^{-1}$ and $\alpha_{\mathrm{s}, 0, \mathrm{X}} \approx 10^{-3}$ for $\mathrm{O}_{3}$ ). The experimental data (Ziemann, 2005) can be matched for $k_{\mathrm{d}, \mathrm{X}}=10^{2} \mathrm{~s}^{-1}$ and $\alpha_{\mathrm{s}, 0, \mathrm{X}}=4.2 \times 10^{-4}$, i.e. for the minimum value for $k_{\mathrm{s}, \mathrm{b}, \mathrm{X}}$ of $9.8 \times 10^{4} \mathrm{~s}^{-1}$ (base case $1, \mathrm{BC} 1$ ). Please note that $\alpha_{\mathrm{s}, 0, \mathrm{X}}$ is a critical parameter with a highly nonlinear impact on chemical losses in both surface and bulk (as shown in the sensitivity study in Sect. 4). For reasonable reaction rate coefficients and $k_{\mathrm{d}, \mathrm{X}}$ values similar to those used in Shiraiwa et al. (2009), experimental data $\left(H_{\mathrm{cp}, \mathrm{X}}\right.$ and the temporal evolution of the oleic acid concentration measured 
by Ziemann, 2005) can be matched for $\alpha_{\mathrm{s}, 0, \mathrm{X}} \approx 4 \times 10^{-4}$ $10^{-3}$. However, it should be noted that the experimental data can also be reproduced with other combinations of $\alpha_{\mathrm{s}, 0, \mathrm{X}}$ and $k_{\mathrm{d}, \mathrm{X}}$, that are closer to predictions from molecular dynamic simulations for related systems (e.g. $\alpha_{\mathrm{s}, 0, \mathrm{X}} \approx 10^{-2}$ and $k_{\mathrm{d}, \mathrm{X}} \approx 10^{9} \mathrm{~s}$; compare Vieceli et al. (2005) for a computational study of ozone at the air-water interface). These aspects will be further investigated in follow-up studies. For $\mathrm{BC} 1$ we chose the lower value for $\alpha_{\mathrm{s}, 0, \mathrm{X}}$ to be able to match the reported bulk reaction rate coefficient, while the higher value for $\alpha_{\mathrm{s}, 0, \mathrm{X}}$ was employed in base case 2 (BC2) with a reduced bulk reactivity (for $\mathrm{BC} 2$ we used $\alpha_{\mathrm{s}, 0, \mathrm{X}}=8.5 \times 10^{-4}$, $k_{\mathrm{d}, \mathrm{X}}=10^{3} \mathrm{~s}^{-1}$ and $k_{\mathrm{s}, \mathrm{b}}=4.85 \times 10^{5} \mathrm{~s}^{-1}$ ).

In analogy to Eq. (27) we can estimate $[\mathrm{X}]_{\mathrm{s}, \max }$

$k_{\mathrm{b}, \mathrm{s}, \mathrm{X}} \times[\mathrm{X}]_{\mathrm{b}, \text { max }}=k_{\mathrm{s}, \mathrm{b}, \mathrm{X}} \times[\mathrm{X}]_{\mathrm{s}, \max }$.

The surface reactivity has been estimated considering experimental values from King et al. (2009) and GonzalezLabrada et al. (2007) for monolayers of oleic acid on an aqueous sub phase: two branches have been found by King et al. (2009) with second-order rate coefficients of $k_{1}=7.3 \times 10^{-11} \mathrm{~cm}^{2} \mathrm{~s}^{-1}$ and $k_{2}=2.1 \times 10^{-12} \mathrm{~cm}^{2} \mathrm{~s}^{-1}$ and branching ratios (for deuterated oleic acid) of $k_{1} / k_{2}=0.86 / 0.14$. Gonzalez-Labrada et al. (2007) reported a rate coefficient of $4.9 \times 10^{-11} \mathrm{~cm}^{2} \mathrm{~s}^{-1}$. Rosen et al. (2008) reported first-order rate coefficients for reactions of $\mathrm{O}_{3}$ with oleic acid on silica and polystyrene latex core particles of $0.64-2.2 \mathrm{~s}^{-1}$ suggesting a much smaller surface rate coefficient of $\sim 1-5 \times 10^{-15} \mathrm{~cm}^{2} \mathrm{~s}^{-1}$ (when assuming saturation of the surface sorption sites). We used $k_{\mathrm{SLR}, \mathrm{X}, \mathrm{Y}}=6 \times 10^{-12} \mathrm{~cm}^{2} \mathrm{~s}^{-1}$ for the surface reaction on a droplet of pure oleic acid which is approximately one order of magnitude below the experimental values reported for oleic acid monolayers on aqueous sub phases. A surface reaction of a pure oleic acid droplet slower than that of a monolayer of oleic acid on an aqueous sub phase can be rationalised since an aqueous sub phase will lead to a reasonably well aligned hydrophobic (but bent) tail of oleic acid containing the reactive site (double bond) sticking out of the liquid phase which is likely to facilitate attack by ozone. In pure oleic acid we would expect a random orientation of oleic acid molecules on the surface and thus a somewhat reduced reactivity. The chosen value for $k_{\mathrm{SLR}, \mathrm{X}, \mathrm{Y}}$ is substantially above the estimated rate coefficient derived from work by Rosen et al. (2008) since SEM images in Rosen et al.'s paper indicate that oleic acid was present in small islands on the particle surface rather than in a layer, so that the number of surface sorption sites is likely to be substantially reduced leading to a higher (but undetermined) rate coefficient.

The bulk reaction rate coefficient for reaction of ozone with oleic acid has been measured by Razumovskii et al. (1972) and confirmed using a "Double Bond Analyser" by Titov et al. (2005) for oleic acid dissolved in $\mathrm{CCl}_{4}$ to be $k_{\mathrm{BR}, \mathrm{X}, \mathrm{Y}}=1.7 \times 10^{-15} \mathrm{~cm}^{3} \mathrm{~s}^{-1}$ (corresponding to the reported value of $1 \times 10^{6} \mathrm{~L} \mathrm{~mol}^{-1} \mathrm{~s}^{-1}$ ). This rate coefficient has been used in many previous studies (e.g. Smith et al., 2002 or King et al., 2009).

In view of the large uncertainty and the lack of experimental data on surface reactivity for droplets of pure oleic acid we chose two base cases for our model validation: in base case 1 (BC1) we employ Titov et al.'s value for $k_{\mathrm{BR}, \mathrm{X}, \mathrm{Y}}$ (together with $k_{\mathrm{d}, \mathrm{X}}=100 \mathrm{~s}^{-1}, \alpha_{s, 0, X}=4.2 \times 10^{-4}$ and $k_{\mathrm{s}, \mathrm{b}, \mathrm{X}}=9.8 \times 10^{4} \mathrm{~s}^{-1}$ ) for the droplet of pure oleic acid to fit the experimental data by Ziemann (2005) and $H_{\mathrm{cp}, \mathrm{X}}$; base case 2 (BC2) uses conditions where bulk and surface reactions are of similar importance assuming $\sim 30$ times lower $k_{\mathrm{BR}, \mathrm{X}, \mathrm{Y}}$ of $5 \times 10^{-17} \mathrm{~cm}^{3} \mathrm{~s}^{-1}$ (together with $k_{\mathrm{d}, \mathrm{X}}=1000 \mathrm{~s}^{-1}$, $\alpha_{\mathrm{s}, 0, \mathrm{X}}=8.5 \times 10^{-4}$ and $\left.k_{\mathrm{s}, \mathrm{b}, \mathrm{X}}=4.85 \times 10^{5} \mathrm{~s}^{-1}\right)$. Further input parameters are detailed in Appendix D.

\section{Simulation results and discussion}

K2-SUB was applied to illustrate the relative importance of surface and bulk losses of the liquid-phase species in different regimes. We simulated experimental data (Ziemann, 2005) in two base cases and then performed detailed sensitivity studies: base case 1 (BC1) assumes fast bulk reaction (using Titov et al.'s value for bulk reactivity) while base case 2 (BC2) illustrates the importance of surface processes in the oleic acid-ozone system at reduced bulk reactivity. Selected results are presented here, while the complete set of data is tabulated in Table 2 and presented in the electronic supplement (see http://www.atmos-chem-phys.net/10/4537/ 2010/acp-10-4537-2010-supplement.zip).

\subsection{Base case 1 (BC1): fast bulk reaction}

In base case 1 the experimental results are matched for $k_{\mathrm{SLR}, \mathrm{X}, \mathrm{Y}}=6 \times 10^{-12} \mathrm{~cm}^{2} \mathrm{~s}^{-1}$ and $k_{\mathrm{BR}, \mathrm{X}, \mathrm{Y}}=1.7 \times 10^{-15}$ $\mathrm{cm}^{3} \mathrm{~s}^{-1}$ as illustrated in Fig. 2a-c. Figure 2a shows the time evolution of the uptake coefficient and the total number of oleic acid molecules as a function of time. The experimental data (presented as black symbols; Ziemann, 2005) is matched by the simulated decay (red line) and the uptake coefficient (black line) shows an initial plateau before dropping off after ca. $30 \mathrm{~s}$. Figure $2 \mathrm{~b}$ illustrates the changes in concentrations of ozone and oleic acid at the surface (red lines) and in the droplet bulk (blue lines). Initially, there is no ozone in the droplet and ozone is taken up into the particle as oleic acid reacts away. Figure $2 \mathrm{c}$ shows the relative importance of bulk and surface processes for the turnover in the droplet. The dashed lines indicate the change in the numbers of oleic acid molecules at the surface (red line) and in the bulk (blue line) as a function of time. For the $0.2 \mu \mathrm{m}$ droplet of pure oleic acid there are obviously many more molecules in the bulk than at the particle surface.

For direct comparison of the rates of conversion at the surface and in the bulk of the particle, we define absolute loss rates (solid lines in Fig. 2c) as the products of 
Table 2. Physico-chemical parameters investigated in the model simulations (base cases and sensitivity studies; the complete set of data is presented in the electronic supplement, see http://www.atmos-chem-phys.net/10/4537/2010/acp-10-4537-2010-supplement.zip).

\begin{tabular}{|c|c|c|c|c|c|c|c|c|c|}
\hline Model scenario & Run & $10^{-5} \frac{r_{\mathrm{p}} /}{\mathrm{m}}$ & $\begin{array}{r}\alpha_{\mathrm{s}, 0, \mathrm{X}} / \\
10^{-4}\end{array}$ & $\begin{array}{r}k_{\mathrm{d}, \mathrm{X}} / \\
10^{2} \mathrm{~s}^{-1}\end{array}$ & $\begin{array}{r}D_{\mathrm{b}, \mathrm{X}} / \\
10^{-5} \mathrm{c} \mathrm{m}^{2} \mathrm{~s}^{-1}\end{array}$ & $\begin{array}{r}D_{\mathrm{b}, \mathrm{Y}} / \\
10^{-10} \mathrm{~cm}^{2} \mathrm{~s}^{-1}\end{array}$ & $\begin{array}{r}k_{\mathrm{s}, \mathrm{b}, \mathrm{X}} / \\
10^{4} \mathrm{~s}^{-1}\end{array}$ & $\begin{array}{r}k_{\mathrm{SLR}, \mathrm{X}, \mathrm{Y}} \\
10^{-12} \mathrm{~cm}^{2} \mathrm{~s}^{-1}\end{array}$ & $\begin{array}{r}k_{\mathrm{BR}, \mathrm{X}, \mathrm{Y}} / \\
10^{-16} \mathrm{~cm}^{3} \mathrm{~s}^{-1}\end{array}$ \\
\hline Base case $1(\mathrm{BC} 1)$ & 1 & 2 & 4.2 & 1 & 1 & 1 & 9.8 & 6 & 17 \\
\hline Bulk reaction only & 2 & 2 & 4.2 & 1 & 1 & 1 & 9.8 & 0 & 17 \\
\hline$k_{\mathrm{SLR}, \mathrm{X}, \mathrm{Y}} / 10$ & 4 & 2 & 4.2 & 1 & 1 & 1 & 9.8 & 0.6 & 17 \\
\hline$k_{\mathrm{SLR}, \mathrm{X}, \mathrm{Y}} \times 10$ & 5 & 2 & 4.2 & 1 & 1 & 1 & 9.8 & 60 & 17 \\
\hline$k_{\mathrm{BR}, \mathrm{X}, \mathrm{Y}} \times 10$ & 6 & 2 & 4.2 & 1 & 1 & 1 & 9.8 & 6 & 170 \\
\hline$H_{\mathrm{cp}, \mathrm{X}} \times 8$ & 9 & 2 & 4.2 & 1 & 1 & 1 & 9.8 & 6 & 17 \\
\hline$[\mathrm{X}]_{\mathrm{gs}} / 10$ & 10 & 2 & 4.2 & 1 & 1 & 1 & 9.8 & 6 & 17 \\
\hline$[\mathrm{X}]_{\mathrm{gs}} \times 10$ & 11 & 2 & 4.2 & 1 & 1 & 1 & 9.8 & 6 & 17 \\
\hline$D_{\mathrm{b}, \mathrm{X}} / 10$ & 12 & 2 & 4.2 & 1 & 0.1 & 1 & 9.8 & 6 & 17 \\
\hline$D_{\mathrm{b}, \mathrm{X}} \times 10$ & 13 & 2 & 4.2 & 1 & 10 & 1 & 9.8 & 6 & 17 \\
\hline$D_{\mathrm{b}, \mathrm{Y}} \times 10^{3}$ & 14 & 2 & 4.2 & 1 & 1 & 1000 & 9.8 & 6 & 17 \\
\hline$k_{\mathrm{d}, \mathrm{X}} \times 2 ; \alpha_{\mathrm{s}, 0, \mathrm{X}} \times 2$ & 19 & 2 & 8.4 & 2 & 1 & 1 & 9.8 & 6 & 17 \\
\hline$k_{\mathrm{s}, \mathrm{b}, \mathrm{X}} / 2 ; \alpha_{\mathrm{s}, 0, \mathrm{X}} \times 2$ & 20 & 2 & 8.4 & 1 & 1 & 1 & 4.9 & 6 & 17 \\
\hline$k_{\mathrm{s}, \mathrm{b}, \mathrm{X}} \times 2 ; \alpha_{\mathrm{s}, 0, \mathrm{X}} / 2$ & 21 & 2 & 2.1 & 1 & 1 & 1 & 19.6 & 6 & 17 \\
\hline $\begin{array}{l}\text { Surface reaction only to } \\
\text { match experiment }\end{array}$ & 22 & 2 & 4.2 & 1 & 1 & 1 & 9.8 & 10 & 0 \\
\hline $\begin{array}{l}\text { Bulk reaction only to match } \\
\text { experiment }\end{array}$ & 23 & 2 & 4.2 & 1 & 1 & 1 & 9.8 & 0 & 18 \\
\hline Base case $2(\mathrm{BC} 2)$ & 24 & 2 & 8.5 & 10 & 1 & 1 & 48.5 & 6 & 0.5 \\
\hline Bulk reaction only & 25 & 2 & 8.5 & 10 & 1 & 1 & 48.5 & 0 & 0.5 \\
\hline Surface reaction only & 26 & 2 & 8.5 & 10 & 1 & 1 & 48.5 & 6 & 0 \\
\hline$k_{\mathrm{SLR}, \mathrm{X}, \mathrm{Y}} / 10$ & 27 & 2 & 8.5 & 10 & 1 & 1 & 48.5 & 0.6 & 0.5 \\
\hline$k_{\mathrm{SLR}, \mathrm{X}, \mathrm{Y}} \times 10$ & 28 & 2 & 8.5 & 10 & 1 & 1 & 48.5 & 60 & 0.5 \\
\hline$D_{\mathrm{b}, \mathrm{Y}} \times 10^{3}$ & 37 & 2 & 8.5 & 10 & 1 & 1000 & 48.5 & 6 & 0.5 \\
\hline$r_{\mathrm{p}} \times 5$ & 38 & 10 & 8.5 & 10 & 1 & 1 & 48.5 & 6 & 0.5 \\
\hline$r_{\mathrm{p}} / 2$ & 39 & 1 & 8.5 & 10 & 1 & 1 & 48.5 & 6 & 0.5 \\
\hline$r_{\mathrm{p}} / 4$ & 40 & 0.5 & 8.5 & 10 & 1 & 1 & 48.5 & 6 & 0.5 \\
\hline$k_{\mathrm{d}, \mathrm{X}} / 2 ; \alpha_{\mathrm{s}, 0, \mathrm{X}} / 2$ & 41 & 2 & 4.25 & 5 & 1 & 1 & 48.5 & 6 & 0.5 \\
\hline$k_{\mathrm{d}, \mathrm{X}} \times 2 ; \alpha_{\mathrm{s}, 0, \mathrm{X}} \times 2$ & 42 & 2 & 17 & 20 & 1 & 1 & 48.5 & 6 & 0.5 \\
\hline$k_{\mathrm{s}, \mathrm{b}, \mathrm{X}} / 2 ; \alpha_{\mathrm{s}, 0, \mathrm{X}} \times 2$ & 43 & 2 & 17 & 10 & 1 & 1 & 24.3 & 6 & 0.5 \\
\hline$k_{\mathrm{s}, \mathrm{b}, \mathrm{X}} \times 2 ; \alpha_{\mathrm{s}, 0, \mathrm{X}} / 2$ & 44 & 2 & 4.25 & 10 & 1 & 1 & 97 & 6 & 0.5 \\
\hline $\begin{array}{l}\text { Surface reaction only to } \\
\text { match experiment }\end{array}$ & 45 & 2 & 8.5 & 10 & 1 & 1 & 48.5 & 10 & 0 \\
\hline $\begin{array}{l}\text { Bulk reaction only to match } \\
\text { experiment }\end{array}$ & 46 & 2 & 8.5 & 10 & 1 & 1 & 48.5 & 0 & 1.2 \\
\hline
\end{tabular}

concentration-based chemical loss rates with the surface area and bulk volume, respectively: $L_{\mathrm{ss}, \mathrm{Y}}^{*}=L_{\mathrm{ss}, \mathrm{Y}} \times A_{\mathrm{ss}}$ and $L_{\mathrm{b}, \mathrm{Y}}^{*}=L_{\mathrm{b}, \mathrm{Y}} \times V_{\mathrm{b}}$. Figure $2 \mathrm{c}$ shows the relative importance of surface and bulk loss: during the first $30 \mathrm{~s}$ initial period ca. twice as many molecules are lost in the bulk than at the surface, and the absolute bulk loss rate remains dominant throughout the model run. 

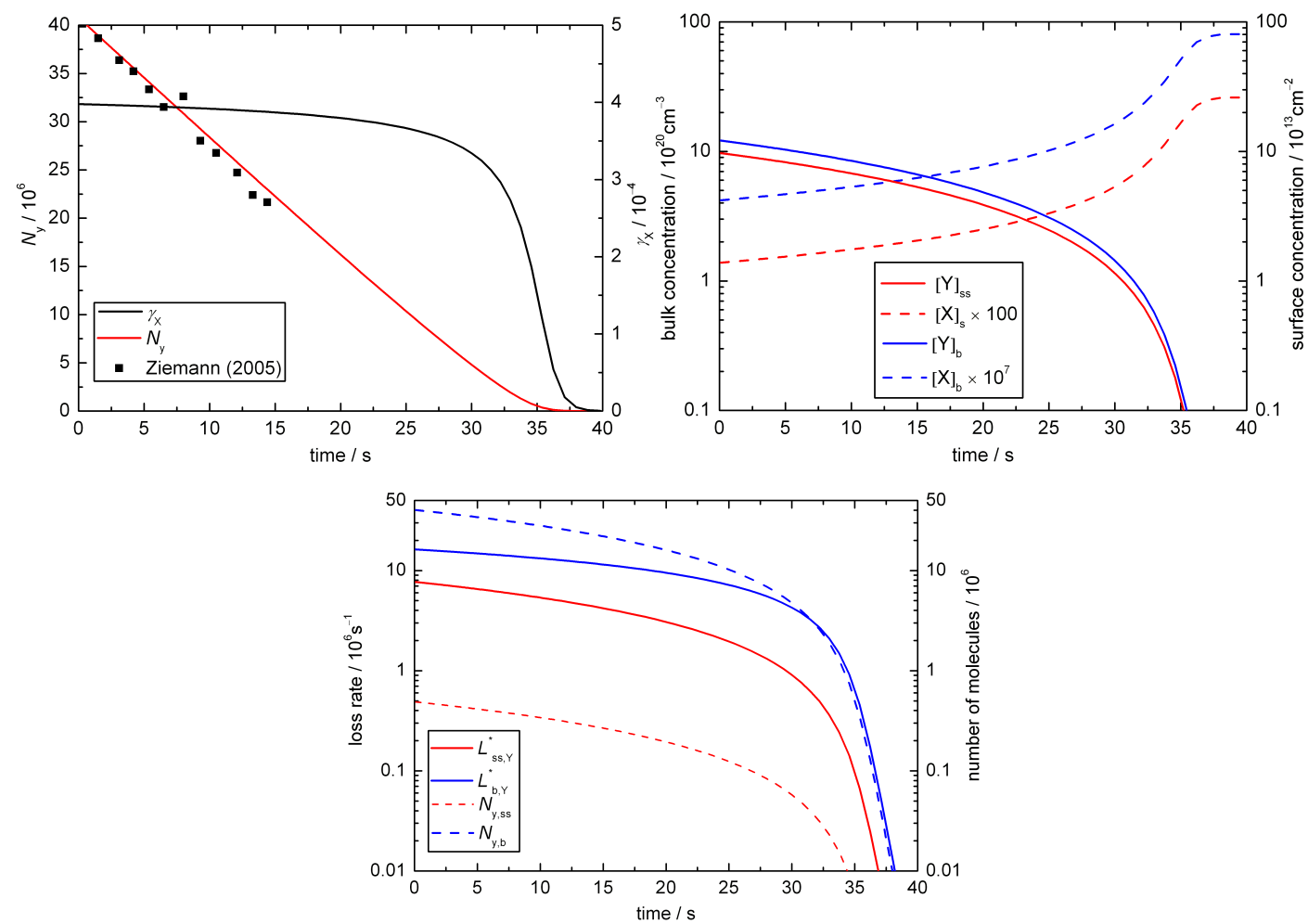

Fig. 2. Temporal evolution of aerosol particle composition and kinetic parameters in base case 1 (BC1; $\mathrm{X}=\mathrm{O}_{3}, \mathrm{Y}=$ oleic acid): (a) ozone uptake coefficient $\left(\gamma_{\mathrm{X}}\right)$ and total number of oleic acid molecules $\left(N_{\mathrm{y}}\right.$; symbols indicate experimental data from Ziemann, 2005); (b) surface and bulk concentrations (square brackets); (c) numbers of oleic acid molecules at the surface and in the bulk of the particle $\left(N_{\mathrm{y}, \mathrm{ss}}, N_{\mathrm{y}, \mathrm{b}}\right)$ and corresponding absolute loss rates $\left(L_{\mathrm{ss}, \mathrm{Y}}^{*}=L_{\mathrm{ss}, \mathrm{Y}} \times A_{\mathrm{ss}}, L_{\mathrm{b}, \mathrm{Y}}^{*}=L_{\mathrm{b}, \mathrm{Y}} \times V_{\mathrm{b}}\right)$.

\section{BC1 sensitivity study}

In order to establish the dependencies of our results on the chosen set of kinetic input parameters for our base model BC1 (justified in Sect. 3 and detailed in Appendix D) we varied all parameters and the complete set of results of these sensitivity studies are presented in the electronic supplement (a summary of the model conditions is given in Table 2). Initially we varied $k_{\mathrm{SLR}, \mathrm{X}, \mathrm{Y}}, k_{\mathrm{BR}, \mathrm{X}, \mathrm{Y}}, K_{\mathrm{sol}, \mathrm{cp}, \mathrm{X}}$, and $[\mathrm{X}]_{\mathrm{gs}}$.

\section{Solubility}

Assuming one order of magnitude difference in the Henry's law coefficients (see Fig. 3a and b) leads to substantial deviations from the experimental data with a higher coefficient showing dramatically faster decay of oleic acid $\left(K_{\mathrm{sol}, \mathrm{cp}, \mathrm{X}}\right.$ could only be increased eight fold, since higher values cause problems for the Matlab solver for long reaction times). This strong dependence on $K_{\text {sol,cp,X }}$ demonstrates that $K_{\text {sol,cp, X }}$ has a larger influence on the decay behaviour than variations in the reaction parameters.

\section{Diffusivity}

We also varied the diffusion coefficients: $D_{\mathrm{b}, \mathrm{X}}$ was altered by one order of magnitude (see Fig. 4a and b) and we increased $D_{\mathrm{b}, \mathrm{Y}}$ by three orders of magnitude (corresponding to the largest oleic acid diffusion coefficient chosen by Smith et al., 2003). A change of $D_{\mathrm{b}, \mathrm{X}}$ leads to a deviation from the experimental data (compare Fig. 4a and b with Fig. 2c), i.e. ozone diffusion has an impact on the turnover in the droplet. Fig. 4b illustrates how for slow diffusion of $X$ the surface loss initially dominates the total loss of $\mathrm{Y}$, while the bulk loss becomes dominant after $\sim 20 \mathrm{~s}$. The figure also suggests that even during the initial surface-dominated decay most molecules that are being lost originate from the bulk, i.e. bulk-to-surface transport of oleic acid is relatively fast and the chemical reaction at the surface is the ratedetermining step. The system is not sensitive even to a three orders of magnitude change of $D_{\mathrm{b}, \mathrm{Y}}$, so that oleic acid diffusion is clearly not limiting the loss of reactants (see run 14 tabulated in Table 2 and illustrated in the electronic supplement, see http://www.atmos-chem-phys.net/10/4537/ 2010/acp-10-4537-2010-supplement.zip). 

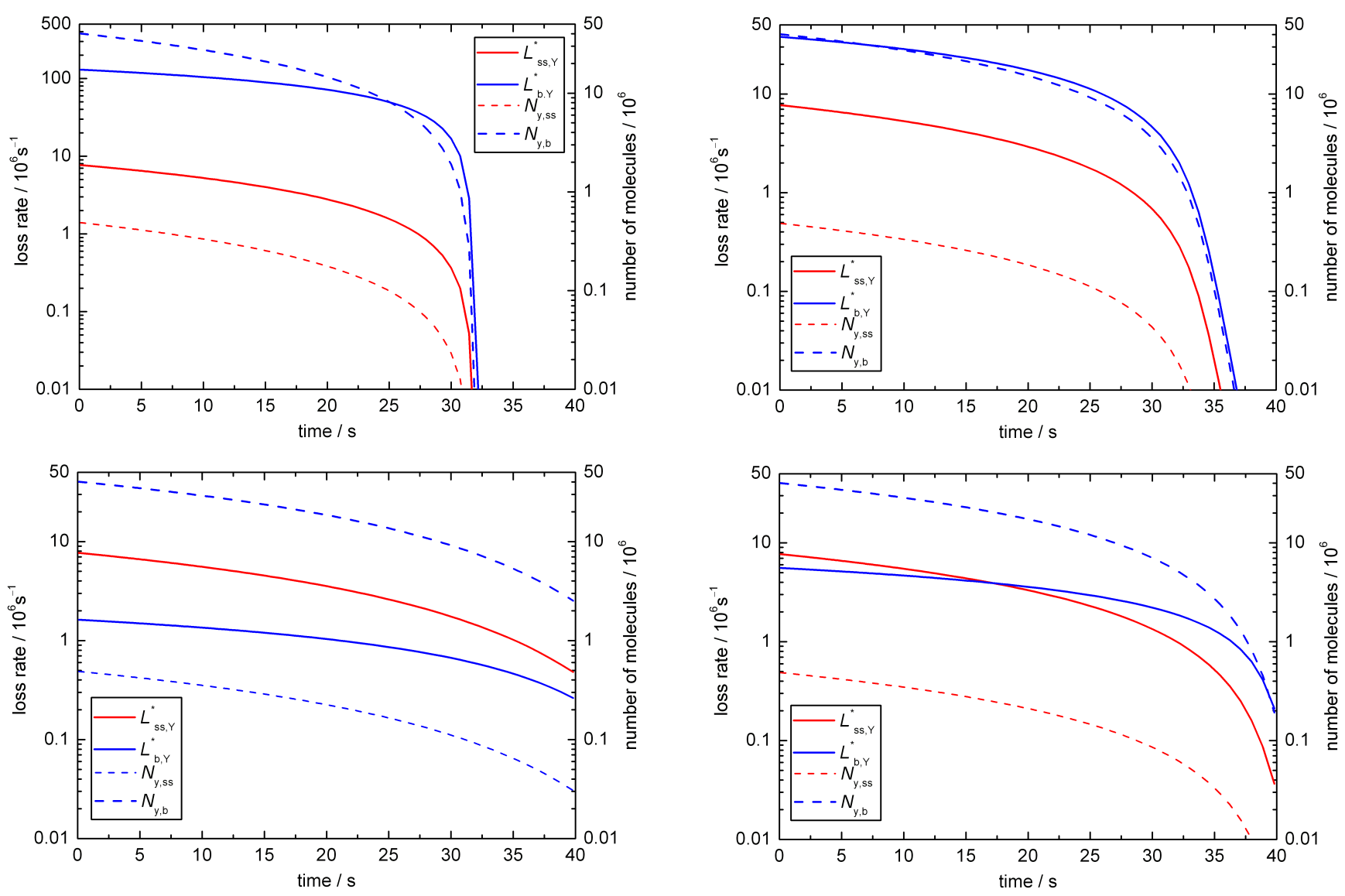

Fig. 3. Temporal evolution of aerosol particle composition and kinetic parameters in sensitivity studies for BC1 with $K_{\text {sol,cp, } \mathrm{X}}$ (a) eight fold above the literature value and (b) ten fold below. Plots are analogous to Fig. 2c.

\section{Particle size}

We tested the model for a range of droplet radii of 1000, 100 and $50 \mathrm{~nm}$ as shown in Fig. 5a-c. Unsurprisingly larger particles require longer reaction times. Due to the change in surface to volume ratio the relative contribution from the surface reaction becomes more important for smaller particles.

\section{Surface accommodation}

For $\mathrm{BC} 1$ the model is relatively insensitive to changes in the rate coefficients for chemical reaction. Under these conditions the reactive decay is limited by transport of ozone into the bulk. The sensitivity studies illustrate that the surface accommodation coefficient $\left(\alpha_{\mathrm{s}, 0, \mathrm{X}}\right)$ is particularly important in this regime: massive deviations are seen when varying $\alpha_{\mathrm{s}, 0, \mathrm{X}}$ (see Fig. 6a and b).

Fig. 4. Temporal evolution of aerosol particle composition and kinetic parameters in sensitivity studies for $\mathrm{BC} 1$ with $D_{\mathrm{b}, \mathrm{X}}$ (a) ten fold above the literature value and (b) ten fold below. Plots are analogous to Fig. 2c.

\section{Exclusive surface or bulk reaction}

As illustrated in Fig. 7, we can also match the experimental results fairly well in sensitivity studies where we assumed that chemical reactions proceed either only at the surface $\left(k_{\mathrm{SLR}, \mathrm{X}, \mathrm{Y}}=1 \times 10^{-11} \mathrm{~cm}^{2} \mathrm{~s}^{-1}\right)$ or only in the bulk (with $k_{\mathrm{BR}, \mathrm{X}, \mathrm{Y}}=1.8 \times 10^{-15} \mathrm{~cm}^{3} \mathrm{~s}^{-1}$ ). Up to $30 \mathrm{~s}$ the temporal evolution of the observable parameters $N_{\mathrm{y}}$ and $\gamma_{\mathrm{X}}$ in both scenarios is similar to each other and to $\mathrm{BC} 1$, but at the end of the model run (after $40 \mathrm{~s}$ ) the surface reaction would still be going on whereas practically all oleic acid would have been consumed in the bulk reaction $\left(N_{\mathrm{y}} \approx 0\right.$ and $\left.\gamma_{\mathrm{x}} \approx 0\right)$. Thus we suggest that future experimental studies should aim at covering longer reaction times to allow for better discrimination of surface and bulk processes.

\subsection{Base case 2 (BC2): slow bulk reaction}

Details of the model and input parameters for base case 2 (BC2) are justified in Sect. 3 and given in Appendix D. Selected results of the calculations are presented 

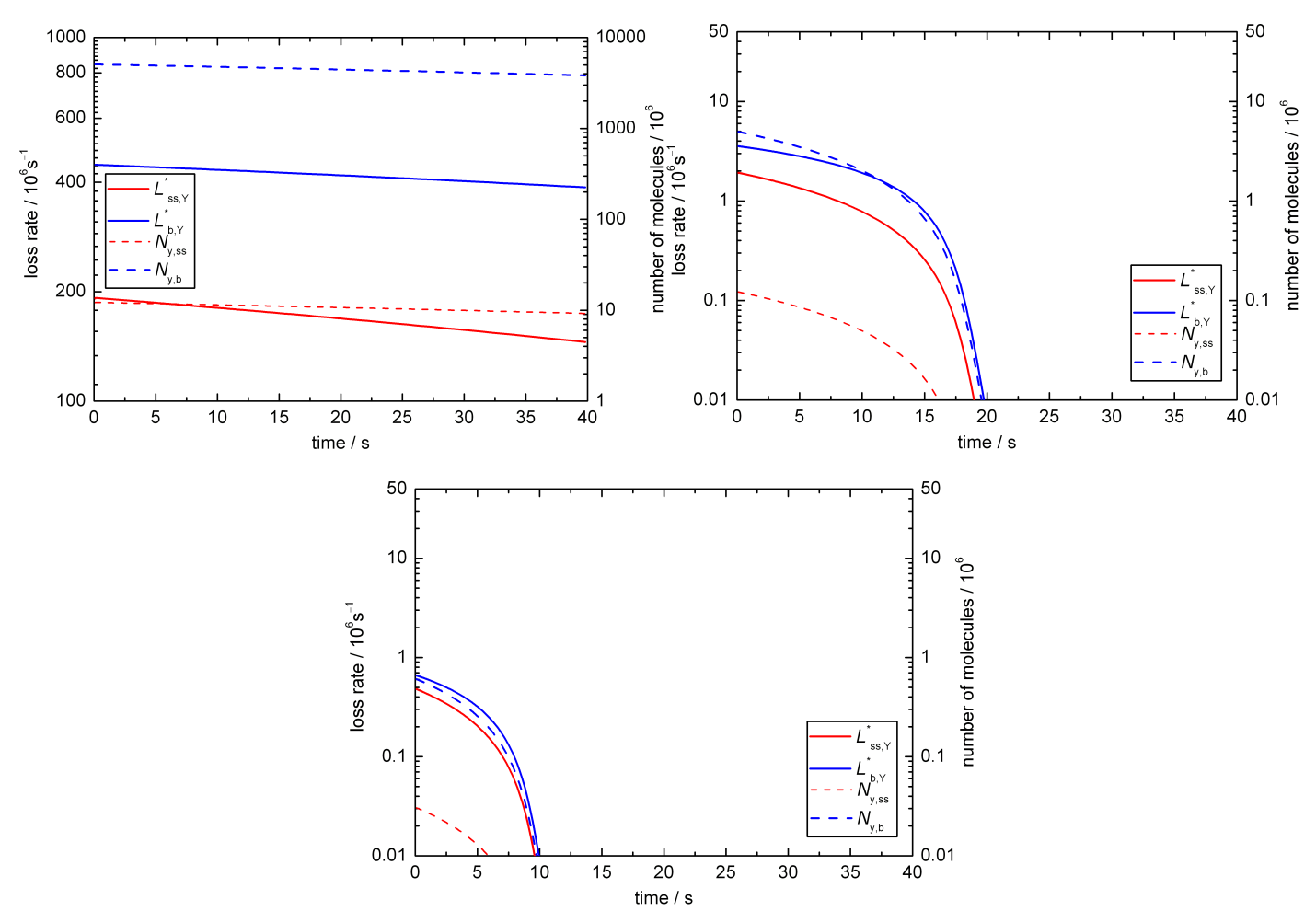

Fig. 5. Temporal evolution of aerosol particle composition and kinetic parameters in sensitivity studies for BC1 with a range of droplet radii: (a) $1000 \mathrm{~nm}$, (b) $100 \mathrm{~nm}$ and (c) $50 \mathrm{~nm}$. Plots are analogous to Fig. $2 \mathrm{c}$.

here (the full data set is presented in the electronic supplement and tabulated in Table 2). Figure 8ac shows that experimental results are matched for the chosen conditions for $k_{\mathrm{SLR}, \mathrm{X}, \mathrm{Y}}=6 \times 10^{-12} \mathrm{~cm}^{2} \mathrm{~s}^{-1}$ and $k_{\mathrm{BR}, \mathrm{X}, \mathrm{Y}}=5 \times 10^{-17} \mathrm{~cm}^{3} \mathrm{~s}^{-1}$. These conditions lead to very similar proportions of absolute bulk and surface loss rates (see solid lines in Fig. 8c).

A general feature of $\mathrm{BC} 2$ compared to $\mathrm{BC} 1$ is the fact that after $\sim 30 \mathrm{~s}$ the decay of oleic acid proceeds much slower (compare e.g. Figs. $2 \mathrm{a}$ and $8 \mathrm{a}$ ). This behaviour can be explained by the different bulk reaction rate coefficients and the temporal evolution of the reacto-diffusive length $\left(l_{\mathrm{rd}, \mathrm{X}}=\sqrt{D_{\mathrm{b}, \mathrm{X}} / k_{\mathrm{b}, \mathrm{X}}}\right)$, which can be regarded as the distance from the surface up to which the chemical reaction proceeds effectively (Finlayson-Pitts and Pitts, 2000; Pöschl et al., 2007).

In $\mathrm{BC} 1$ the bulk reaction rate coefficient is high $\left(k_{\mathrm{BR}, \mathrm{X}, \mathrm{Y}}=1.7 \times 10^{-15} \mathrm{~cm}^{3} \mathrm{~s}^{-1}\right)$ but the initial value of $l_{\mathrm{rd}, \mathrm{X}}$ is as small as $\sim 20 \mathrm{~nm}$, indicating that the reaction proceeds fast but only close to the surface. After $\sim 30 \mathrm{~s}, l_{\mathrm{rd}, \mathrm{X}}$ increases steeply and oleic acid is quickly depleted throughout the bulk of the particle.

In $\mathrm{BC} 2$ the bulk reaction rate coefficient is by a factor of $\sim 30$ lower $\left(k_{\mathrm{BR}, \mathrm{X}, \mathrm{Y}}=5 \times 10^{-17} \mathrm{~cm}^{3} \mathrm{~s}^{-1}\right)$ and the initial value of $l_{\mathrm{rd}, \mathrm{X}}$ is as large as $\sim 130 \mathrm{~nm}$, indicating that the reaction proceeds slow and throughout the bulk of the particle. Due to the low value of $k_{\mathrm{BR}, \mathrm{X}, \mathrm{Y}}$ the depletion of oleic acid continues to proceed slowly also after $\sim 30 \mathrm{~s}$. Further details and effects of bulk reactivity, concentration gradients and diffusion are explored and discussed in a follow-up study (Shiraiwa et al., 2010).

\section{BC2 sensitivity study}

In order to establish the dependencies of our results on the chosen set of kinetic input parameters for $\mathrm{BC} 2$ we varied all parameters and detailed results of this sensitivity study are presented in the electronic supplement together with those for BC1.

First we varied $k_{\mathrm{SLR}, \mathrm{X}, \mathrm{Y}}, k_{\mathrm{BR}, \mathrm{X}, \mathrm{Y}}, K_{\mathrm{sol}, \mathrm{cp}, \mathrm{X}}$, and $[\mathrm{X}]_{\mathrm{gs}}$. The model is clearly sensitive to small changes in the reactivity both on the surface and in the bulk of the droplet (much more so than $\mathrm{BC} 1$ : compare runs 4-7 with runs 27-30 tabulated in Table 2 and illustrated in the electronic supplement, see http://www.atmos-chem-phys.net/10/4537/ 2010/acp-10-4537-2010-supplement.zip), so that the model results deviate substantially for the low and high rate coefficients tested.

\section{Solubility}

The effect of changing the Henry's law coefficients by $\sim$ one order of magnitude is even stronger than that for $\mathrm{BC} 1$ 
which can be attributed to the fact that the reaction proceeds throughout the bulk of the particle and is not limited by the reacto-diffusive length $\left(l_{\mathrm{rd}, \mathrm{X}}\right)$ as discussed above (Sect. 4.2.).

\section{Diffusivity}

A reduction of the diffusion coefficient $D_{\mathrm{b}, \mathrm{X}}$ does show a small deviation from the experimental data, while an increase results in no significant deviation, i.e. ozone diffusion has a small impact on the turnover in the droplet. The system is not sensitive even to three orders of magnitude larger $D_{\mathrm{b}, \mathrm{Y}}$, so that oleic acid diffusion is again not limiting the loss of reactants.

\section{Particle size}

We also tested the model for a range of droplet radii of 1000 , 100 and $50 \mathrm{~nm}$ showing a similar picture to $\mathrm{BC} 1$ (compare runs $38-40)$.

\section{Surface accommodation}

In base case 2 surface and bulk reaction rate coefficients become both much more important than in $\mathrm{BC} 1$. The turnover in the droplet is thus not limited by transport, but by chemical reaction. Nevertheless, the assumed value for $\alpha_{\mathrm{s}, 0, \mathrm{X}}$ remains important.

Our study underlines the strong influence of $\alpha_{\mathrm{s}, \mathrm{X}}$ in all conditions which becomes apparent when inspecting Eq. (19): $\alpha_{\mathrm{s}, \mathrm{X}}$ appears in all terms and our modelling results demonstrate its highly non-linear impact on reactive losses in atmospheric particles. More experimental data are needed to better pin down $\alpha_{\mathrm{s}, 0, \mathrm{X}}$. Our analysis also demonstrates that it is vital to use a model when designing an experimental study to be able to choose the most insightful experimental conditions: $\mathrm{BC} 1$ and $\mathrm{BC} 2$ show substantial deviations for reaction times above $\sim 30 \mathrm{~s}$, but experimental data are only available for the first $15 \mathrm{~s}$, so that both base cases fit the experiment. $\mathrm{BC} 1$ accommodates the fast bulk reaction rate coefficient reported by Titov et al. (2005), while BC2 is compatible with the experimental data only for substantially slower bulk reaction.

\section{Exclusive surface or bulk reaction}

The experimental results, i.e. the first $15 \mathrm{~s}$ of oleic acid decay, can also be matched when assuming exclusive surface or bulk reaction (see Fig. 9a and b) with $k_{\mathrm{SLR}, \mathrm{X}, \mathrm{Y}}=1 \times 10^{-11} \mathrm{~cm}^{2} \mathrm{~s}^{-1}$ or $k_{\mathrm{BR}, \mathrm{X}, \mathrm{Y}}=1.2 \times 10^{-16} \mathrm{~cm}^{3} \mathrm{~s}^{-1}$, respectively. These results indicate for both base cases (BC1 and $\mathrm{BC} 2$ ) that the surface reaction of a pure oleic acid droplet is slower than that of a monolayer of oleic acid on an aqueous sub phase (compare Gonzalez-Labrada et al., 2007 and King et al., 2009) which can be rationalised by the lack of alignment of oleic acid molecules in organic rather than aqueous solution. This
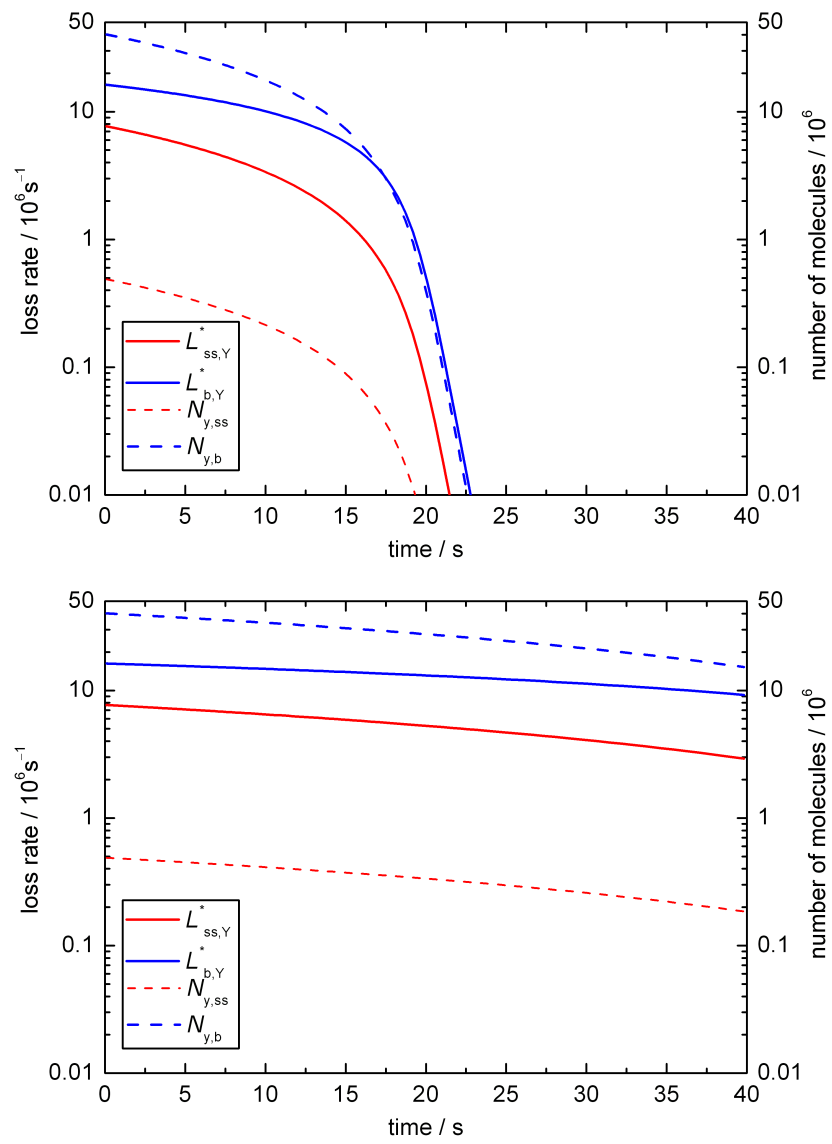

Fig. 6. Temporal evolution of aerosol particle composition and kinetic parameters in sensitivity studies for BC1 for (a) doubling and (b) halving $\alpha_{\mathrm{s}, 0, \mathrm{X}}$ (while compensating with $k_{\mathrm{d}, \mathrm{X}}$ to maintain agreement with the experimental Henry's law coefficient $H_{\mathrm{cp}, \mathrm{X}}$ ). Plots are analogous to Fig. 2c.

different orientation is likely to reduce the surface reactivity (compare discussion in Sect. 3). Overall, the results suggest an upper limit for the surface reaction of $\sim 1 \times 10^{-11} \mathrm{~cm}^{2} \mathrm{~s}^{-1}$ for the chosen set of input parameters. However, it should be noted that the upper limit for the surface rate coefficient would be $\sim$ one order of magnitude higher if the desorption lifetime of ozone at the interface would be as short as nanoto pico-seconds (compare Vieceli et al., 2005 for a study of ozone at the air-water interface). Vieceli et al. (2004) found that the collision rate between ozone and a double bond is sensitive to several factors, including the extent of localization of the double bonds in the system and the distance that ozone diffuses into the organic phase. These aspects will be further investigated in follow-up studies.

\subsection{Comparison with literature: surface vs. bulk reactivity and secondary chemistry}

Hearn et al. (2005) studied the reaction of polydisperse oleic acid particles (mean radii $\sim 400 \mathrm{~nm}$ ) with ozone in an aerosol 

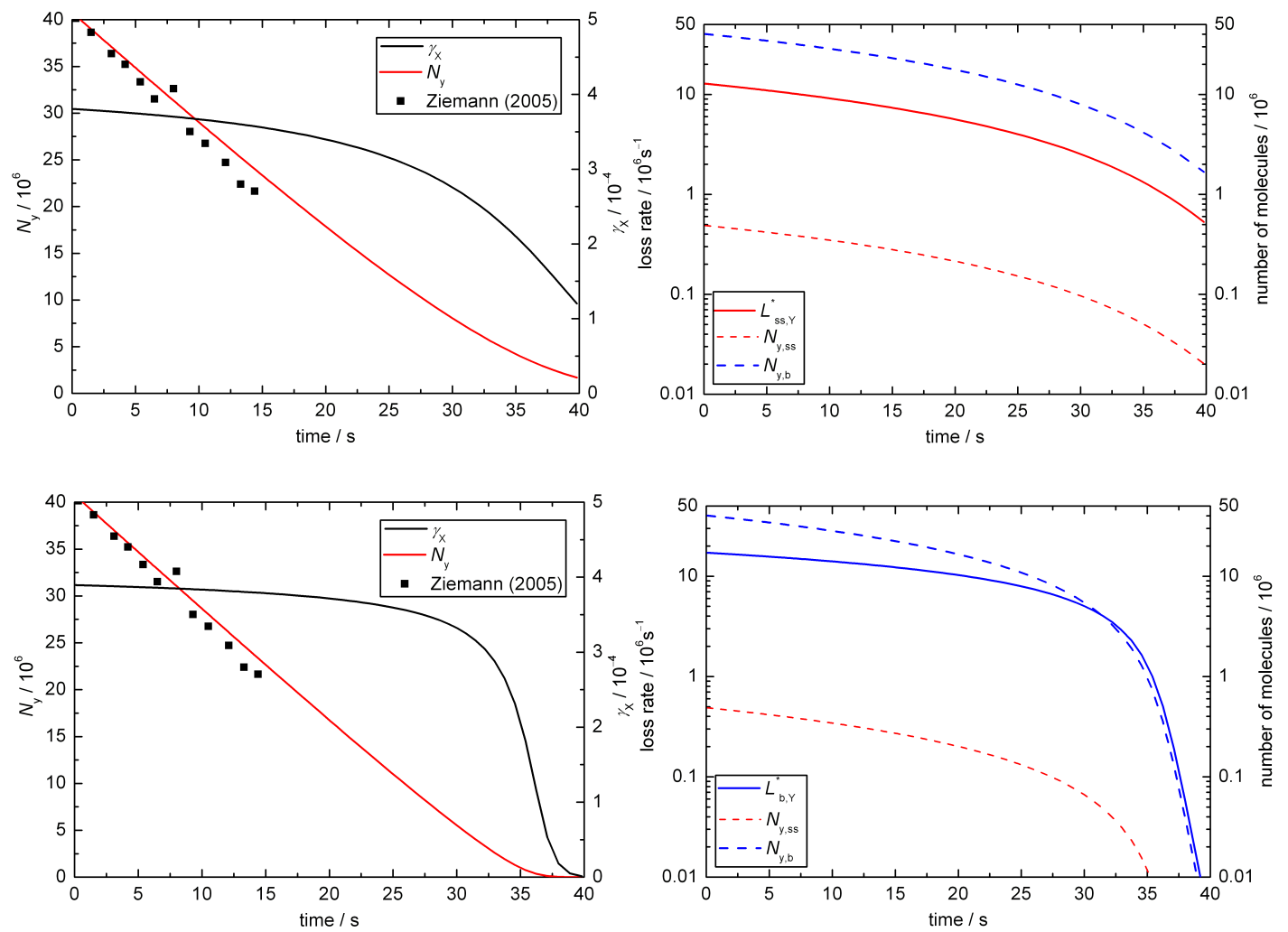

Fig. 7. Temporal evolution of aerosol particle composition and kinetic parameters in sensitivity studies for BC1 with chemical reaction occurring only at the surface (a-b) or only in the bulk (c-d). Plots are analogous to Fig. 2a and Fig. 2c.

chemical ionisation mass spectrometer. The reaction was found to occur at the particle surface although previous measurements suggested bulk reactivity (Moise and Rudich, 2002; Morris et al., 2002; Smith et al., 2002; Thornberry and Abbatt, 2004; Vieceli et al., 2004). Hearn et al. attribute this discrepancy to a reduced rate of ozone diffusion into the bulk caused by pure oleic acid behaving like a solid rather than a disordered liquid. This would result in a surface-dominated reaction between ozone and the double bond of oleic acid. Hearn et al. (2005) suggest that most of the reactions occur in the first monolayer. Knopf et al. (2005) studied $\mathrm{O}_{3}$ uptake by multi-component mixtures containing oleic acid and found that physical state and microstructure of these mixtures are of key importance. Low fractions of added solid components decreased the uptake by one order of magnitude compared to liquid mixtures. Furthermore, solid-liquid mixtures showed an increased uptake with increasing film age. McNeill et al. (2007) studied the reaction of ozone with internally mixed submicron aqueous droplets containing sodium oleate. They found evidence for a surface process and suggest that a Langmuir-Hinshelwood model may be applied with ozone first adsorbing to the surface before the reaction takes place. The measured rate coefficient was found to reach a plateau for high $\left[\mathrm{O}_{3}\right]$. McNeill et al. (2007) suggest that oleate predominantly reacts in a monolayer on the aqueous sub-phase with reactive sites residing in a liquid- like film with ozone diffusing through the film and out again while the surface to which ozone adsorbs might be changing over the course of the reaction. Other studies also suggest that changes in ozone diffusion or solubility might occur during reaction (e.g. Moise and Rudich, 2000; Hearn et al., 2005). More importantly, a disruption of the order of the oleic acid dimers by surface-active reaction products might lead to a transition from surface-dominated reaction to bulk reaction (Hearn et al., 2005). Experimental evidence in support of this suggestion has recently been provided by King et al. (2009): a monolayer of oleic acid on an aqueous subphase is replaced by a new monolayer during $\mathrm{O}_{3}$-initiated oxidation. Intriguingly, no product film has been found in studies of the ozonolysis of the methyl ester of oleic acid (Pfrang et al., 2010). Grimm et al. (2006) studied 1-2 mm droplets and found that ozone may penetrate up to $10 \mu \mathrm{m}$ into these particles suggesting a bulk-phase process for atmospherically relevant aerosol droplets.

McNeill et al. (2008) investigated the heterogeneous $\mathrm{OH}$ oxidation of palmitic acid as a function of the particle size. Their experimental results are consistent with a model considering surface-only reactions with volatilisation of products, surface renewal and secondary chemistry between palmitic acid and the oxidation products. This study suggests that heterogeneous oxidation rates of organic aerosol are fastest for materials present at the particle surface, rather 

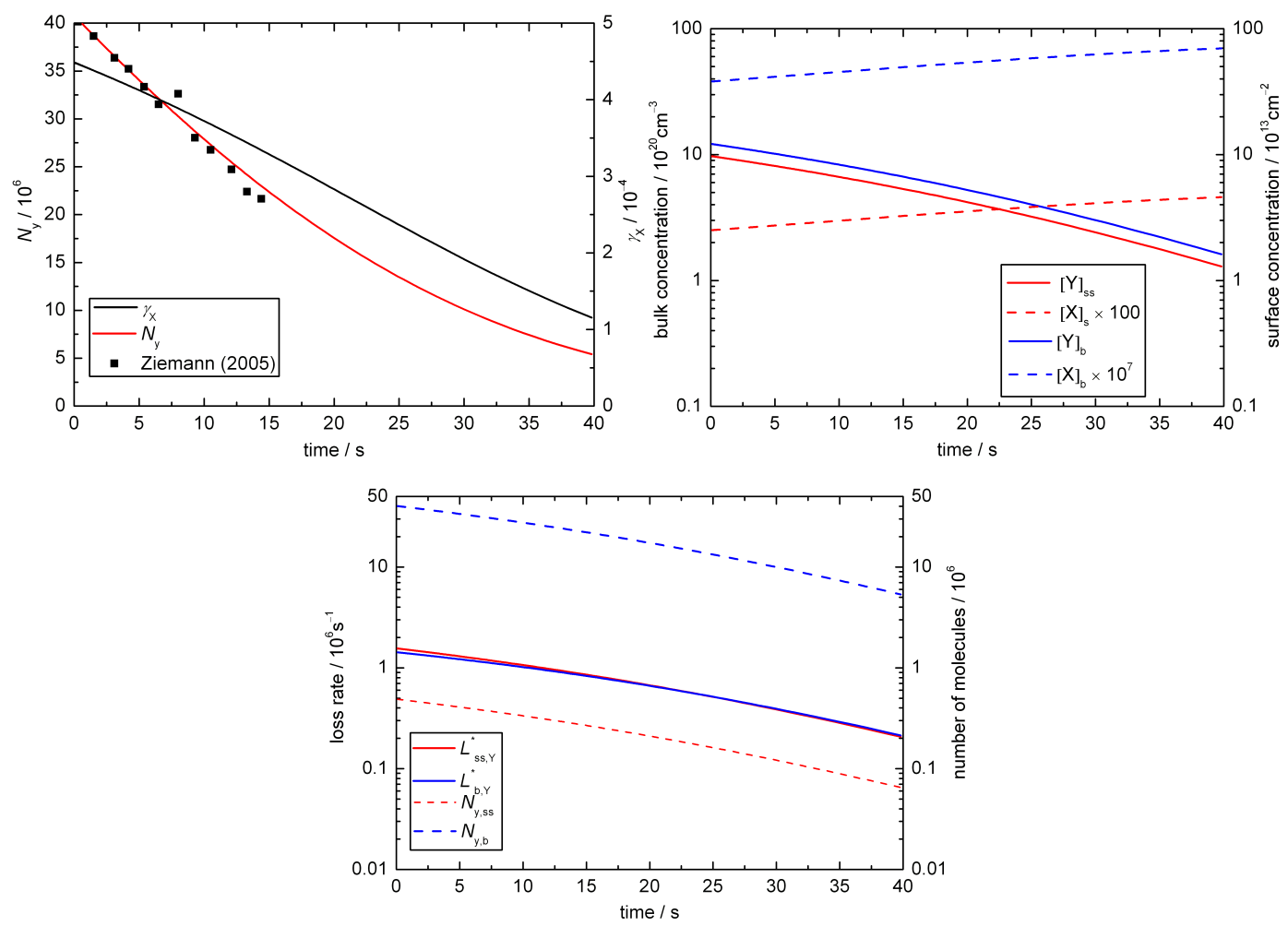

Fig. 8. Temporal evolution of aerosol particle composition and kinetic parameters in base case 2 (BC2; $\mathrm{X}=\mathrm{O}_{3}, \mathrm{Y}=$ oleic acid): (a) ozone uptake coefficient $\left(\gamma_{\mathrm{X}}\right)$ and total number of oleic acid molecules $\left(N_{\mathrm{y}}\right.$; symbols indicate experimental data from Ziemann, 2005); (b) surface and bulk concentrations (square brackets); (c) numbers of oleic acid molecules at the surface and in the bulk of the particle $\left(N_{\mathrm{y}, \mathrm{ss}}, N_{\mathrm{y}, \mathrm{b}}\right)$ and corresponding absolute loss rates $\left(L_{\mathrm{ss}, \mathrm{Y}}^{*}=L_{\mathrm{ss}, \mathrm{Y}} \times A_{\mathrm{ss}}, L_{\mathrm{b}, \mathrm{Y}}^{*}=L_{\mathrm{b}, \mathrm{Y}} \times V_{\mathrm{b}}\right)$.

than in the bulk. The gradient in oxidation rates is steepest for solid particles such as palmitic acid. Liquid particles - such as the oleic acid droplets considered in our study show more shallow gradients between surface and bulk rates (McNeill et al., 2008). Our model analysis demonstrates indeed that bulk reactivity is of key importance at least for oleic acid particles with radii of $200 \mathrm{~nm}$ or larger. There is evidence for the occurrence of surface renewal in our model system: the comparison of the absolute loss rates to the number of molecules at the particle surface and in the bulk (see e.g. Fig. 8c) suggests significant bulk-surface transport (bulk transport will be considered explicitly in the KM-SUB model).

Criegee intermediates are suggested to lead to a significant additional loss of oleic acid, e.g. $36 \%$ of the oleic acid molecules were attributed to reaction of oleic acid with a Criegee intermediate rather than with ozone (Hearn et al., 2005) confirming an earlier study by Hearn and Smith (2004). Interference of secondary reactions by Criegee intermediates was also found by Hung and Ariya (2007). Recently, Sage et al. (2009) not only confirmed the occurrence of secondary reactions of Criegee intermediates with the organic acid, but also found evidence for additional, previously unrecognised secondary chemistry that might involve the car- bon backbone. Secondary chemistry is not currently considered in our model, but could be implemented if kinetic parameters for secondary reactions in the ozone-oleic acid system would become available (Hearn et al., 2005 quantified the loss due to secondary reaction by comparing methyl oleate and oleic acid reactivities, but could not measure the rate coefficient for the secondary process). Secondary chemistry would suggest an even slower initial reaction, so that the upper limit determined for the surface reaction in our model study would remain valid.

The chemical composition of the particle will obviously change over the course of the reaction and the extent of the deviation from initial particle composition will become increasingly significant for longer reaction timescales. Dominant initial products from the ozonolysis of oleic acid are known to be nonanal, which is likely to evaporate, as well as 9-oxononanoic, nonanoic, and azelaic acids in the liquid phase (e.g. Rudich et al., 2007; Vesna et al., 2009). We expect first-generation products other than nonanal to remain in the particle. Renewal of the surface layer by evaporation is thus unlikely to accelerate the oxidation process substantially. The evaporation of products from particle to gas phase is not considered in the current model, but we are planning to incorporate evaporation and condensation in follow-up 

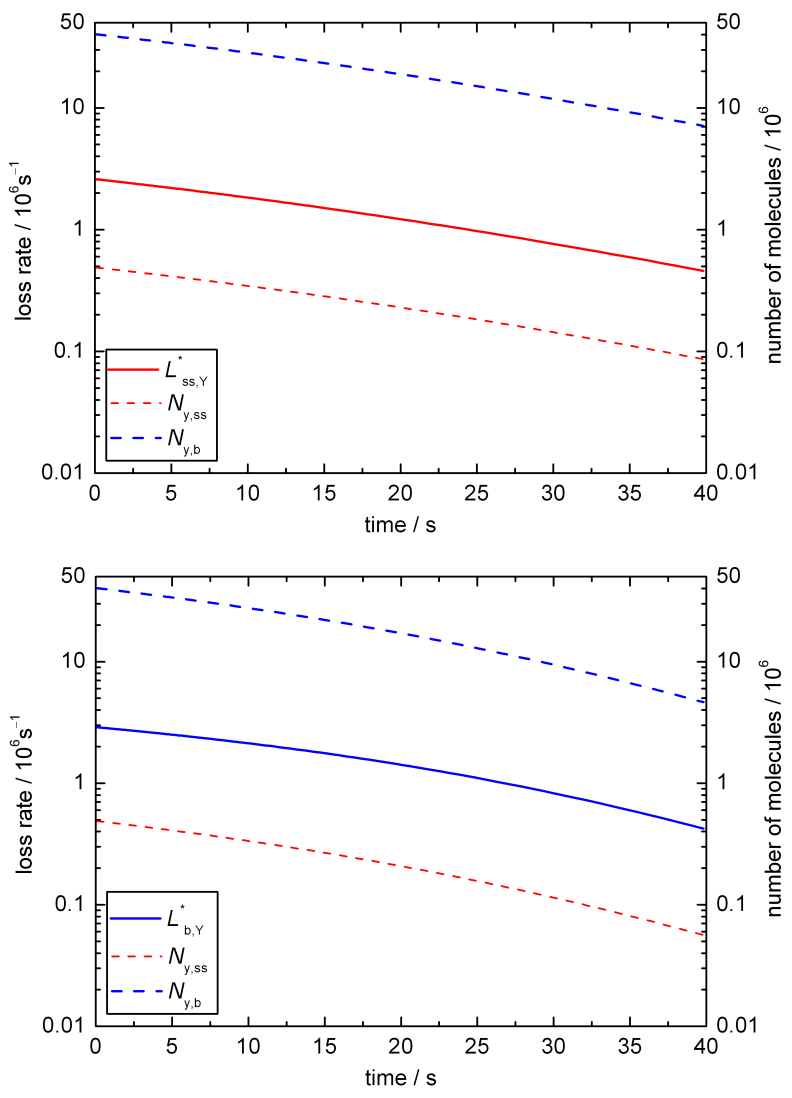

Fig. 9. Temporal evolution of aerosol particle composition and kinetic parameters in sensitivity studies for BC2 with chemical reaction occurring (a) only at the surface or (b) only in the bulk. Plots are analogous to Fig. 2c.

studies. The influence of the changing chemical composition of the particle surface on adsorbate-surface interactions i.e. on the surface accommodation coefficient can be taken into account by describing $\alpha_{\mathrm{s}, 0, \mathrm{X}}$ as a linear combination of the initial surface accommodation coefficients that would be observed on pure substrates made up by the different surface components $Y_{p}$ weighted by their fractional surface area $\theta_{\mathrm{ss}, \mathrm{Y}_{\mathrm{p}}}$ (Pöschl et al., 2007; discussed in detail in Shiraiwa et al., 2010):

$\alpha_{\mathrm{s}, 0, \mathrm{X}}=\sum_{\mathrm{p}} \alpha_{\mathrm{s}, 0, \mathrm{X}, \mathrm{Y}_{\mathrm{p}}} \theta_{\mathrm{ss}, \mathrm{Y}_{\mathrm{p}}}$.

In a similar way, the influence of changing chemical composition of the particle bulk on the bulk diffusion coefficient can be taken into account by describing $D_{\mathrm{b}, \mathrm{X}}$ as a linear combination of the initial bulk diffusion coefficients that would be observed in pure bulk:

$D_{\mathrm{b}, \mathrm{X}}=\sum_{\mathrm{p}} D_{\mathrm{b}, \mathrm{X}, \mathrm{Y}_{\mathrm{p}}} \Phi_{\mathrm{b}, \mathrm{Y}_{\mathrm{p}}}$.

$\Phi_{b, Y p}$ refers to the fraction of $Y_{p}$ in the bulk. For the base cases presented in this paper, $\alpha_{\mathrm{s}, 0, \mathrm{X}}$ and $D_{\mathrm{b}, \mathrm{X}}$ are assumed to be constant for simplicity. Bulk diffusion of the liquid phase species can be corrected in analogy to Eq. (32) for the gas-phase compound (see Shiraiwa et al., 2010). However, the diffusion of oleic acid is not resolved in K2-SUB to maintain compatibility with resistor model formulations. Bulk diffusion of oleic acid is explicitly included in the KMSUB model (Shiraiwa et al., 2010) and corrections for the changing chemical composition in the liquid phase could efficiently be implemented in KM-SUB. For long reaction times, the increasing proportion of products in the particle will also introduce additional uncertainties in the calculations since branching ratios and molecular properties are less well known in particular for second- and third-generation products.

It is apparent that discrepancies remain between the large number of studies of the $\mathrm{O}_{3}$-oleic acid system. K2-SUB can be used to design, interpret and analyse future experimental investigations to allow choosing most insightful experimental conditions and de-convoluting surface and bulk processes.

While our modelling approach maintains compatibility with previous resistor-model formulations (e.g. Worsnop et al., 2002; Smith et al., 2002; King et al., 2008, 2009) K2SUB enables free variation of all relevant parameters and thus can describe not only limiting cases, but also any state in between those. The testing and application of different sets of equations for different limiting cases used previously is adequate for the analysis of certain laboratory data, but it appears not to be well suited for efficient modelling of different types of clouds and aerosols under varying atmospheric conditions. Simulations for various multi-component and multiphase reaction systems that are much more realistic models for atmospheric aerosol can be performed in future, incremental developments of K2-SUB. Such extensions would not be straight forward - if at all possible - for resistor-based models. Many experimental and nearly all atmospheric systems do not adhere to ideal limiting-case behaviour, so that K2-SUB is a potentially powerful tool to help improving our understanding of interfacial oxidation processes of atmospheric importance.

\section{Conclusions}

1. We demonstrate how a detailed treatment of adsorption and reaction at the surface can be coupled to a description of bulk reaction and transport that is consistent with traditional resistor model formulations. To our knowledge, K2-SUB is the first model in which this coupling has been realised.

2. From literature data we have derived a set of kinetic parameters that enable detailed description of mass transport and chemical reaction on the surface and in the bulk of oleic acid particles. 
3. The available reaction rate coefficients support that chemical reaction in the bulk plays an important role. Due to the wide range of rate coefficients reported from the different experimental studies, however, the exact proportion between surface and bulk reaction remains uncertain. Our model runs suggest for the chosen set of input parameters that the surface reaction rate coefficient is not significantly above $1 \times 10^{-11} \mathrm{~cm}^{2} \mathrm{~s}^{-1}$ for droplets of pure oleic acid.

4. Test calculations showed that the surface accommodation coefficient of the gas-phase reactant has a strong non-linear influence on the surface and bulk reactions. Our two base cases demonstrate how slight variations in $\alpha_{\mathrm{s}, 0, \mathrm{X}}$ lead to either transport-limited (BC1) or reactionlimited (BC2) systems.

5. Further experimental data are required to establish the relative contributions of surface and bulk processes to the loss of oleic acid and other organic species in atmospheric aerosols.

6. We propose that K2-SUB may be used to design, interpret and analyse experiments for better discrimination between surface and bulk processes in the oleic acidozone system as well as in other heterogeneous reaction systems. For example, the model results suggest that longer reaction times than investigated in earlier studies ( $>30 \mathrm{~s}$ for $200 \mathrm{~nm}$ particles at $2.8 \mathrm{ppm}\left[\mathrm{O}_{3}\right]$ ) are needed to unravel the proportions between surface and bulk reaction. Many experimental and nearly all atmospheric reaction systems do not adhere to ideal limiting-case behaviour tailor-made for traditional resistor model formulations, so that K2-SUB is a potentially powerful tool to help improving our understanding of interfacial oxidation processes of atmospheric importance.

\section{Supplementary material}

The complete set of results of the model runs tabulated in Table 2 is presented in the electronic supplement (see http://www.atmos-chem-phys.net/10/4537/2010/ acp-10-4537-2010-supplement.zip) as 138 gif image files (three plots per model run equivalent to those exemplified in Fig. 2a, b and c).

\section{Appendix A}

\section{List of symbols}

\begin{tabular}{lll}
\hline Symbol & Meaning & SI Unit \\
\hline$\alpha_{\mathrm{S}, 0, \mathrm{X}}$ & $\begin{array}{l}\text { initial surface accommoda- } \\
\text { tion coefficient of X }\end{array}$ \\
$\alpha_{\mathrm{s}, \mathrm{X}}$ & $\begin{array}{l}\text { surface accommodation co- } \\
\text { efficient of } \mathrm{X}\end{array}$
\end{tabular}

www.atmos-chem-phys.net/10/4537/2010/

\begin{tabular}{|c|c|c|}
\hline$\gamma_{\mathrm{x}}$ & $\begin{array}{l}\text { uptake coefficient of X (nor- } \\
\text { malized by gas kinetic flux }\end{array}$ & \\
\hline$\gamma_{\mathrm{b}, \mathrm{X}}$ & $\begin{array}{l}\text { of surface collisions) } \\
\text { resistor model conductance } \\
\text { of particle bulk diffusion and } \\
\text { reaction of X }\end{array}$ & \\
\hline$\gamma_{\mathrm{g}, \mathrm{X}}$ & $\begin{array}{l}\text { resistor model conductance } \\
\text { of gas phase diffusion of } X\end{array}$ & \\
\hline$\gamma_{\mathrm{s}, \mathrm{X}}$ & $\begin{array}{l}\text { resistor model conductance } \\
\text { of surface reaction of } X\end{array}$ & \\
\hline$\gamma_{\mathrm{s}, \mathrm{b}, \mathrm{x}}$ & $\begin{array}{l}\text { resistor model conductance } \\
\text { of surface-bulk transfer of } X\end{array}$ & \\
\hline$\delta_{\mathrm{X}}$ & $\begin{array}{l}\text { effective molecular diameter } \\
\text { of } X\end{array}$ & $\mathrm{~m}$ \\
\hline$\delta_{\mathrm{Y}}$ & $\begin{array}{l}\text { effective molecular diameter } \\
\text { of } Y\end{array}$ & $\mathrm{~m}$ \\
\hline$\sigma_{\mathrm{s}, \mathrm{X}}$ & $\begin{array}{l}\text { molecular cross section of } \mathrm{X} \\
\text { in the sorption layer }\end{array}$ & $\mathrm{m}^{2}$ \\
\hline$\sigma_{\mathrm{ss}, \mathrm{Y}}$ & $\begin{array}{l}\text { molecular cross section of } Y \\
\text { in the quasi-static layer }\end{array}$ & $\mathrm{m}^{2}$ \\
\hline $\begin{array}{l}\tau_{\mathrm{d}, \mathrm{X}} \\
\Phi_{\mathrm{b}, \mathrm{Y}_{\mathrm{p}}}\end{array}$ & $\begin{array}{l}\text { desorption lifetime of } X \\
\text { fraction of } Y_{p} \text { in the bulk }\end{array}$ & $\mathrm{s}$ \\
\hline$\omega_{\mathrm{x}}$ & $\begin{array}{l}\text { mean thermal velocity of } X \\
\text { in the gas phase }\end{array}$ & $\mathrm{m} \mathrm{s}^{-1}$ \\
\hline$A_{\mathrm{ss}}$ & $\begin{array}{l}\text { Particle surface area } \\
\left(A_{\mathrm{ss}}=4 \pi r_{\mathrm{p}}^{2}\right)\end{array}$ & $\mathrm{m}^{2}$ \\
\hline$C_{\mathrm{b}, \mathrm{rd}, \mathrm{X}}$ & $\begin{array}{l}\text { reacto-diffusive geometry } \\
\text { correction factor of } X\end{array}$ & \\
\hline$C_{\mathrm{g}, \mathrm{X}}$ & $\begin{array}{l}\text { gas phase diffusion correc- } \\
\text { tion factor of } X\end{array}$ & \\
\hline$D_{\mathrm{b}, \mathrm{X}}$ & $\begin{array}{l}\text { particle bulk diffusion coef- } \\
\text { ficient of X }\end{array}$ & $\mathrm{m}^{2} \mathrm{~s}^{-1}$ \\
\hline$D_{\mathrm{g}, \mathrm{X}}$ & $\begin{array}{l}\text { gas phase diffusion coeffi- } \\
\text { cient of } X\end{array}$ & $\mathrm{~m}^{2} \mathrm{~s}^{-1}$ \\
\hline$H_{\mathrm{cp}, \mathrm{X}}$ & $\begin{array}{l}\text { Henry's law coefficient of } X \\
\text { (concentration/pressure) }\end{array}$ & $\mathrm{mol} \mathrm{m}^{-3} \mathrm{~Pa}^{-1}$ \\
\hline$J_{\mathrm{ads}, \mathrm{X}}, J_{\mathrm{des}, \mathrm{X}}$ & $\begin{array}{l}\text { flux of adsorption and des- } \\
\text { orption of X }\end{array}$ & $\mathrm{m}^{-2} \mathrm{~s}^{-1}$ \\
\hline$J_{\mathrm{b}, \mathrm{rd}, \mathrm{X}}$ & $\begin{array}{l}\text { reacto-diffusive flux of } X \text { in } \\
\text { the particle bulk }\end{array}$ & $\mathrm{m}^{-2} \mathrm{~s}^{-1}$ \\
\hline$J_{\mathrm{b}, \mathrm{s}, \mathrm{X}}, J_{\mathrm{s}, \mathrm{b}, \mathrm{X}}$ & $\begin{array}{l}\text { flux of bulk-surface and } \\
\text { surface-bulk transfer of } \mathrm{X} \\
\text { (sorption layer) }\end{array}$ & $\mathrm{m}^{-2} \mathrm{~s}^{-1}$ \\
\hline$J_{\mathrm{b}, \mathrm{ss}, \mathrm{Y}}, J_{\mathrm{ss}, \mathrm{b}, \mathrm{Y}}$ & $\begin{array}{l}\text { flux of bulk-surface and } \\
\text { surface-bulk transfer of } \mathrm{Y} \\
\text { (quasi-static layer) }\end{array}$ & $\mathrm{m}^{-2} \mathrm{~s}^{-1}$ \\
\hline$J_{\text {coll, } \mathrm{X}}$ & $\begin{array}{l}\text { gas kinetic flux of X collid- } \\
\text { ing with the surface }\end{array}$ & $\mathrm{m}^{-2} \mathrm{~s}^{-1}$ \\
\hline$J_{\mathrm{s}, \mathrm{b}, \text { net, } \mathrm{X}}$ & $\begin{array}{l}\text { net flux of surface-bulk } \\
\text { transfer of X }\end{array}$ & $\mathrm{m}^{-2} \mathrm{~s}^{-1}$ \\
\hline$k_{\mathrm{a}, \mathrm{X}}$ & $\begin{array}{l}\text { first-order adsorption rate } \\
\text { coefficient of } X\end{array}$ & $\mathrm{~m} \mathrm{~s}^{-1}$ \\
\hline$k_{\mathrm{a}, 0, \mathrm{X}}$ & $\begin{array}{l}\text { first-order adsorption rate } \\
\text { coefficient of } \mathrm{X} \text { on an } \\
\text { adsorbate-free surface }\end{array}$ & $\mathrm{m} \mathrm{s}^{-1}$ \\
\hline$k_{\mathrm{b}, \mathrm{X}}$ & $\begin{array}{l}\text { pseudo-first-order rate coef- } \\
\text { ficient for chemical loss of } X \\
\text { in the particle bulk }\end{array}$ & $\mathrm{s}^{-1}$ \\
\hline$k_{\mathrm{b}, \mathrm{s}, \mathrm{X}}$ & $\begin{array}{l}\text { first-order rate coefficient } \\
\text { for bulk-to-surface transfer } \\
\text { of } X\end{array}$ & $\mathrm{~m} \mathrm{~s}^{-1}$ \\
\hline$k_{\mathrm{b}, \mathrm{ss}, \mathrm{Y}}$ & $\begin{array}{l}\text { first-order rate coefficient } \\
\text { for bulk-to-surface transfer } \\
\text { of Y }\end{array}$ & $\mathrm{m} \mathrm{s}^{-1}$ \\
\hline
\end{tabular}

Atmos. Chem. Phys., 10, 4537-4557, 2010 


\begin{tabular}{|c|c|c|c|c|c|}
\hline$k_{\mathrm{d}, \mathrm{X}}$ & $\begin{array}{l}\text { first-order desorption rate } \\
\text { coefficient of } X\end{array}$ & $\mathrm{~s}^{-1}$ & {$[\mathrm{X}]_{\mathrm{gs}}$} & $\begin{array}{l}\text { near-surface gas phase num- } \\
\text { ber concentration of } X\end{array}$ & $\mathrm{~m}^{-3}$ \\
\hline$k_{\mathrm{BR}, \mathrm{X}, \mathrm{Y}}$ & $\begin{array}{l}\text { second order bulk reaction } \\
\text { rate coefficient }\end{array}$ & $\mathrm{m}^{3} \mathrm{~s}^{-1}$ & {$[\mathrm{X}]_{\mathrm{S}}$} & $\begin{array}{l}\text { surface number concentra- } \\
\text { tion of } X \text { (sorption layer) }\end{array}$ & $m^{-2}$ \\
\hline$k_{\mathrm{s}, \mathrm{X}}$ & $\begin{array}{l}\text { pseudo-first-order rate coef- } \\
\text { ficient for chemical loss of } X \\
\text { in the sorption layer }\end{array}$ & $\mathrm{s}^{-1}$ & {$[\mathrm{X}]_{\mathrm{S}, \max }$} & $\begin{array}{l}\text { maximum surface number } \\
\text { concentration of } X \text { (sorption } \\
\text { layer) }\end{array}$ & $\mathrm{m}^{-2}$ \\
\hline$k_{\mathrm{s}, \mathrm{b}, \mathrm{X}}$ & $\begin{array}{l}\text { first-order rate coefficient } \\
\text { for surface-to-bulk transfer }\end{array}$ & $\mathrm{s}^{-1}$ & $\mathrm{Y}$ & $\begin{array}{l}\text { non-volatile molecular } \\
\text { species }\end{array}$ & \\
\hline$k_{\mathrm{s}, \mathrm{b}, \text { net } \mathrm{X}}$ & $\begin{array}{l}\text { of X } \\
\text { pseudo-first-order rate co- }\end{array}$ & $\mathrm{s}^{-1}$ & {$[\mathrm{Y}]_{\mathrm{ss}}$} & $\begin{array}{l}\text { surface number concentra- } \\
\text { tion of } \mathrm{Y} \text { (quasi-static layer) }\end{array}$ & $\mathrm{m}^{-2}$ \\
\hline & $\begin{array}{l}\text { efficient for net surface-to- } \\
\text { bulk transfer of } X\end{array}$ & & {$[\mathrm{Y}]_{\mathrm{ss}, 0}$} & $\begin{array}{l}\text { initial surface number con- } \\
\text { centration of } Y \text { (quasi-static }\end{array}$ & $\mathrm{m}^{-2}$ \\
\hline$k_{\mathrm{ss}, \mathrm{Y}}$ & pseudo-first-order rate coef- & $s^{-1}$ & & layer) & \\
\hline & $\begin{array}{l}\text { ficient for chemical loss of } \\
\text { Yin the quasi-static surface } \\
\text { layer }\end{array}$ & & {$[\mathrm{Y}]_{\mathrm{ss}, \max }$} & $\begin{array}{l}\text { max. surface number con- } \\
\text { centration of } Y \text { (quasi-static } \\
\text { layer) }\end{array}$ & $\mathrm{m}^{-2}$ \\
\hline$k_{\mathrm{ss}, \mathrm{b}, \mathrm{Y}}$ & $\begin{array}{l}\text { first-order rate coefficients } \\
\text { for surface-bulk transfer of } \\
\text { Y }\end{array}$ & $\mathrm{s}^{-1}$ & {$[\mathrm{Y}]_{\mathrm{b}}$} & $\begin{array}{l}\text { average concentration of } \mathrm{Y} \\
\text { across the whole particle } \\
\text { bulk (including near-surface }\end{array}$ & $\mathrm{m}^{-2}$ \\
\hline$k_{\mathrm{SLR}, \mathrm{X}, \mathrm{Y}}$ & second-order rate coefficient & $\mathrm{m}^{2} \mathrm{~s}^{-1}$ & & bulk) & \\
\hline & $\begin{array}{l}\text { for surface layer reactions of } \\
\text { X with Y }\end{array}$ & & {$[\mathrm{Y}]_{\mathrm{b}, 0}$} & $\begin{array}{l}\text { initial concentration of } \mathrm{Y} \\
\text { across the whole particle }\end{array}$ & $\mathrm{m}^{-2}$ \\
\hline$K_{\mathrm{ads}, \mathrm{X}}^{\prime}$ & $\begin{array}{l}\text { effective adsorption equilib- } \\
\text { rium constant of } X\end{array}$ & $\mathrm{~m}^{3}$ & & $\begin{array}{l}\text { bulk (including near-surface } \\
\text { bulk) }\end{array}$ & \\
\hline$K_{\text {sol,cp, } \mathrm{X}}$ & $\begin{array}{l}\text { solubility or gas-particle } \\
\text { partitioning coefficient of } X\end{array}$ & $\mathrm{~mol} \mathrm{~m}^{-3} \mathrm{~Pa}^{-1}$ & {$[\mathrm{Y}]_{\mathrm{b}, \max }$} & $\begin{array}{l}\text { max. concentration of } \mathrm{Y} \\
\text { across the whole particle }\end{array}$ & $\mathrm{m}^{-2}$ \\
\hline$K_{\mathrm{sol}, \mathrm{cc}, \mathrm{X}}$ & $\begin{array}{l}\text { dimensionless solubility or } \\
\text { gas-particle partitioning co- }\end{array}$ & & & $\begin{array}{l}\text { bulk (including near-surface } \\
\text { bulk) }\end{array}$ & \\
\hline
\end{tabular}

\section{Appendix B}

\section{Relevant equations from PRA framework (Pöschl et al., 2007)}

$\gamma_{\mathrm{x}}=\alpha_{\mathrm{s}, \mathrm{X}} \frac{k_{\mathrm{s}, \mathrm{X}}+k_{\mathrm{s}, \mathrm{b}, \text { net }, \mathrm{X}}}{k_{\mathrm{s}, \mathrm{X}}+k_{\mathrm{s}, \mathrm{b}, \text { net }, \mathrm{X}}+k_{\mathrm{d}, \mathrm{X}}}$

with

$k_{\mathrm{s}, \mathrm{b}, \text { net }, \mathrm{X}}=k_{\mathrm{s}, \mathrm{b}, \mathrm{X}}\left(1+\frac{k_{\mathrm{b}, \mathrm{s}, \mathrm{X}}}{C_{\mathrm{b}, \mathrm{rd}, \mathrm{X}} \sqrt{k_{\mathrm{b}, \mathrm{X}} D_{\mathrm{b}, \mathrm{X}}}}\right)^{-1}$,

and the reacto-diffusive geometry correction factor (conversion from planar to spherical geometry; determined by the particle radius, $r_{\mathrm{p}}$, and the reacto-diffusive length for species $\mathrm{X}: l_{\mathrm{rd}, \mathrm{X}}=\sqrt{\left.\overline{D_{\mathrm{b}, \mathrm{X}} / k_{\mathrm{b}, \mathrm{X}}}\right)}$ :

$C_{\mathrm{b}, \mathrm{rd}, \mathrm{X}}=\operatorname{coth}\left(\frac{r_{\mathrm{p}}}{l_{\mathrm{rd}, \mathrm{X}}}\right)-\frac{l_{\mathrm{rd}, \mathrm{X}}}{r_{\mathrm{p}}}$.

$K_{\text {sol,cp,X }}$ is the solubility or gas-particle partitioning coefficient for $\mathrm{X}$ and describes the partitioning of a volatile species between gas phase and particle bulk (at infinite dilution, it equals Henry's law coefficient; $K_{\mathrm{sol}, \mathrm{cp}, \mathrm{X}} R T=K_{\mathrm{sol}, \mathrm{cc}, \mathrm{X}}$ giving the ratio of condensed phase and gas phase concentrations)

$K_{\mathrm{sol}, \mathrm{cc}, \mathrm{X}}=K_{\mathrm{sol}, \mathrm{cp}, \mathrm{X}} R T=\frac{k_{\mathrm{s}, \mathrm{b}, \mathrm{X}}}{k_{\mathrm{b}, \mathrm{s}, \mathrm{X}}} \frac{k_{\mathrm{a}, \mathrm{X}}}{k_{\mathrm{d}, \mathrm{X}}}=\frac{k_{\mathrm{s}, \mathrm{b}, \mathrm{X}}}{k_{\mathrm{b}, \mathrm{s}, \mathrm{X}}} \frac{\alpha_{\mathrm{s}, \mathrm{X}} \omega_{\mathrm{X}}}{4 k_{\mathrm{d}, \mathrm{X}}}$ 


$$
\begin{aligned}
& k_{\mathrm{a}, 0, \mathrm{X}}=\alpha_{\mathrm{s}, 0, \mathrm{X}} \frac{\omega_{\mathrm{x}}}{4} \\
& \alpha_{\mathrm{s}, \mathrm{X}}=\alpha_{\mathrm{s}, 0, \mathrm{X}}\left(1-\theta_{\mathrm{s}, \mathrm{X}}\right) \\
& K_{\mathrm{ads}, \mathrm{X}}^{\prime}=\frac{\sigma_{\mathrm{x}} k_{\mathrm{a}, 0, \mathrm{X}}}{k_{\mathrm{d}, \mathrm{X}}+k_{\mathrm{s}, \mathrm{X}}+k_{\mathrm{s}, \mathrm{b}, \mathrm{net}, \mathrm{X}}} \\
& \frac{[\mathrm{X}]_{\mathrm{bs}}}{[\mathrm{X}]_{\mathrm{s}}}=\frac{k_{\mathrm{s}, \mathrm{b}, \mathrm{X}}}{k_{\mathrm{b}, \mathrm{s}, \mathrm{X}}+C_{\mathrm{b}, \mathrm{rd}, \mathrm{X}} \sqrt{k_{\mathrm{b}, \mathrm{X}} D_{\mathrm{b}, \mathrm{X}}}}
\end{aligned}
$$

\section{Appendix C}

\section{Resistor model formulations and the PRA framework}

The description of heterogeneous reactions is often achieved by resistor model formulations (e.g. Worsnop et al., 2002; Smith et al., 2002; King et al, 2008, 2009; Gross et al., 2009) which are valid under certain assumptions and consistent with the PRA framework as described under Special Case B in Pöschl et al. (2007). Uptake coefficients $(\gamma)$ generally refer to a gas-phase species $\mathrm{X}$. A sorption layer uptake coefficient can be defined under steady state condition by Eq. (B1) (compare Pöschl et al., 2007, Eq. 115). Resistor model formulation of Special Case B in Pöschl et al. (2007) is obtained from inversion of Eq. (B1):

$$
\frac{1}{\gamma_{\mathrm{x}}}=\frac{1}{\alpha_{\mathrm{s}, \mathrm{X}}}+\frac{1}{\Gamma_{\mathrm{s}, \mathrm{X}}+\frac{1}{\frac{1}{\Gamma_{\mathrm{s}, \mathrm{b}, \mathrm{X}}}+\frac{1}{\Gamma_{\mathrm{b}, \mathrm{X}}}}}
$$

with resistor model conductance terms for surface reaction $\left(\Gamma_{\mathrm{s}, \mathrm{X}}\right)$ for surface-bulk transfer $\left(\Gamma_{\mathrm{s}, \mathrm{b}, \mathrm{X}}\right)$ and for particle bulk diffusion and reaction $\left(\Gamma_{\mathrm{b}, \mathrm{X}}\right)$ (as defined in Eqs. 21, 22 and 23)

$$
\Gamma_{\mathrm{b}, \mathrm{X}}=\frac{4}{\omega_{x}} K_{\mathrm{sol}, \mathrm{cp}, \mathrm{X}} R T C_{\mathrm{b}, \mathrm{rd}, \mathrm{X}} \sqrt{k_{\mathrm{b}, \mathrm{X}} D_{\mathrm{b}, \mathrm{X}}}
$$

Equation (C2) is equivalent to resistor model formulations, exemplified here by the treatment used by Smith et al. (2002; Eq. 4):

$$
\begin{array}{rll}
\Gamma_{\mathrm{rxn}}= & \frac{4 H R T D}{\bar{c} l}[\operatorname{coth}(a / l-l / a)] \\
& k_{\mathrm{b}, \mathrm{X}}= & k_{2} \text { [Oleic] } \\
& l_{\mathrm{rd}, \mathrm{X}}= & l \\
& \omega_{\mathrm{X}}= & \bar{c} \\
\text { with } & r_{\mathrm{p}}= & a \\
& K_{\mathrm{sol}, \mathrm{cp}, \mathrm{X}}= & H \\
& D_{\mathrm{b}, \mathrm{X}}= & D \\
& \gamma_{\mathrm{rxn}}= & \Gamma_{\mathrm{b}, \mathrm{X}}
\end{array}
$$

and $\quad C_{\mathrm{b}, \mathrm{rd}, \mathrm{X}}=\quad \operatorname{coth}\left(\frac{a}{l}\right)-\frac{l}{a}$; compare Eq. (B3).

\section{C1 For reaction of ozone near the particle surface}

Case $1 \mathrm{~b}$ in Smith et al., 2002; for $l_{\mathrm{rd}, \mathrm{X}}<r_{\mathrm{p}} / 20$; diffusionlimited case. The uptake is given by (Smith et al., 2002, Eqs. 9 and $\mathrm{C} 2$ )

$\gamma=\frac{4 H R T}{\bar{c}} \sqrt{D k_{2}} \sqrt{[\text { Oleic }]} \cong \frac{4}{\omega_{\mathrm{x}}} K_{\mathrm{sol}, \mathrm{cp}, \mathrm{X}} R T \sqrt{k_{\mathrm{b}, \mathrm{X}} D_{\mathrm{b}, \mathrm{X}}}$

with $1 \leq C_{\mathrm{b}, \mathrm{rd}, \mathrm{X}} \geq 0.95 \approx 1$.

Derivation:

Limiting case for $l_{\mathrm{rd}, \mathrm{X}}=r_{\mathrm{p}} / 20$ in Eq. (C2) with $C_{\mathrm{b}, \mathrm{rd}, \mathrm{X}}$ as defined in Eq. (B3) and $\operatorname{coth}\left(20 r_{\mathrm{p}} / r_{\mathrm{p}}\right)=\frac{e^{40}+1}{e^{40}-1} \approx 1$, thus $C_{\mathrm{b}, \mathrm{rd}, \mathrm{X}}=1-\frac{1}{20}=0.95$, and for $l_{\mathrm{rd}, \mathrm{X}}<r_{\mathrm{p}} / 20: C_{\mathrm{b}, \mathrm{rd}, \mathrm{X}} \approx 1$.

\section{C2 For fast diffusion of ozone through the particle}

Case 1a in Smith et al., 2002; for $l_{\mathrm{rd}, \mathrm{X}}>r_{\mathrm{p}}$; reaction not limited by diffusion) the uptake is given by

$\gamma=\frac{4 H R T}{\bar{c}} \frac{a}{3} k_{2}[$ Oleic $] \cong \frac{4}{3 \omega_{\mathrm{x}}} K_{\mathrm{sol}, \mathrm{cp}, \mathrm{X}} R T r_{\mathrm{p}} k_{\mathrm{b}, \mathrm{X}}$.

Derivation:

$\operatorname{coth} x=\cosh x / \sinh x$; Taylor series: $\operatorname{coth} x \cong 1 / x+x / 3-$ $x^{3} / 45 \ldots$

Using Taylor and neglecting all terms higher than power 1 in $x$ :

$$
\begin{gathered}
C_{\mathrm{b}, \mathrm{rd}, \mathrm{X}}=\operatorname{coth}\left(\frac{r_{\mathrm{p}}}{l_{\mathrm{rd}, \mathrm{X}}}\right)-\frac{l_{\mathrm{rd}, \mathrm{X}}}{r_{\mathrm{p}}} \approx\left(\frac{l_{\mathrm{rd}, \mathrm{X}}}{r_{\mathrm{p}}}+\frac{r_{\mathrm{p}}}{3 l_{\mathrm{rd}, \mathrm{X}}}\right) \\
-\frac{l_{\mathrm{rd}, \mathrm{X}}}{r_{\mathrm{p}}}=\frac{r_{\mathrm{p}}}{3 l_{\mathrm{rd}, \mathrm{X}}} .
\end{gathered}
$$

Equation (C2) thus becomes:

$$
\Gamma_{\mathrm{b}, \mathrm{X}}=\frac{4}{\omega_{\mathrm{x}}} K_{\mathrm{sol}, \mathrm{cp}, \mathrm{X}} R T \frac{r_{\mathrm{p}}}{3 l_{\mathrm{rd}, \mathrm{X}}} \sqrt{k_{\mathrm{b}, \mathrm{X}} D_{\mathrm{b}, \mathrm{X}}} .
$$

Using Eq. (C4):

$$
\begin{aligned}
\Gamma_{\mathrm{b}, \mathrm{X}} & =\frac{4}{\omega_{\mathrm{x}}} K_{\mathrm{sol}, \mathrm{cp}, \mathrm{X}} R T \frac{r_{\mathrm{p}} \sqrt{k_{\mathrm{b}, \mathrm{X}} D_{\mathrm{b}, \mathrm{X}}}}{3 D_{\mathrm{b}, \mathrm{X}}} \sqrt{k_{\mathrm{b}, \mathrm{X}} D_{\mathrm{b}, \mathrm{X}}} \\
& =\frac{4}{3 \omega_{\mathrm{x}}} K_{\mathrm{sol,cp}, \mathrm{X}} R T r_{\mathrm{p}} k_{\mathrm{b}, \mathrm{X}} .
\end{aligned}
$$

\section{C3 For the reactive uptake being dominated by reaction} at the surface

Case 2 in Smith et al., 2002; bulk reaction and conductance term are assumed to be negligible, i.e. uptake is assumed to 
be equal to surface conductance term

$$
\begin{aligned}
\gamma & =\Gamma_{\mathrm{s}, \mathrm{X}}=\frac{k_{2}^{\text {surf }}\left[\mathrm{O}_{3}\right]_{\text {surf }}[\text { Oleic }]_{\text {surf }}}{\text { normalised by gas }- \text { collision rate }} \\
& =\frac{k_{2}^{\text {surf }}\left(P_{\mathrm{O}_{3}} H \delta_{\mathrm{X}}\right)[\text { Oleic }] \delta_{\mathrm{X}}}{P_{\mathrm{O}_{3}} / 4 R T} \\
& =\frac{4 H R T}{\bar{c}} \delta_{\mathrm{X}}^{2} k_{2}^{\text {surf }}[\text { Oleic }] \cong \frac{4 k_{\mathrm{a}, \mathrm{X}}}{\omega_{\mathrm{X}}} \frac{k_{\mathrm{s}, \mathrm{X}}}{k_{\mathrm{d}, \mathrm{X}}} .
\end{aligned}
$$

Derivation:

$$
\text { - } k_{\mathrm{s}, \mathrm{X}}=k_{2}^{\mathrm{surf}}[\mathrm{Oleic}] \delta_{\mathrm{X}}
$$

- HRT $\delta_{\mathrm{X}}=K_{\mathrm{sol}, \mathrm{cp}, \mathrm{X}} R T \delta_{\mathrm{X}}=K_{\mathrm{sol}, \mathrm{cc}, \mathrm{X}} \delta_{\mathrm{X}}=\frac{k_{\mathrm{s}, \mathrm{b}, \mathrm{X}}}{k_{\mathrm{b}, \mathrm{s}, \mathrm{X}}} \frac{k_{\mathrm{a}, \mathrm{X}}}{k_{\mathrm{d}, \mathrm{X}}} \delta_{\mathrm{X}}$ and $\frac{k_{\mathrm{b}, \mathrm{S}, \mathrm{X}}}{k_{\mathrm{s}, \mathrm{b}, \mathrm{X}}}=\delta_{\mathrm{X}}$ so that $H R T \delta_{\mathrm{X}}=\frac{k_{\mathrm{a}, \mathrm{X}}}{k_{\mathrm{d}, \mathrm{X}}}$ (compare Eqs. B4, 21 and 30).

\section{Appendix D}

\section{Model input parameters}

K2-SUB model input parameters for the investigated chemical species $\left(\mathrm{X}=\mathrm{O}_{3}\right.$ and $\mathrm{Y}=$ oleic acid) based on experimental data from Ziemann (2005), Smith et al. (2002), Gonzalez-Labrada et al. (2007), King et al. $(2008,2009)$ and Pöschl et al. (2001).

$$
\begin{aligned}
& r_{\mathrm{p}}=\quad 0.2 \mu \mathrm{m} \text { (Ziemann, 2005) } \\
& D_{\mathrm{b}, \mathrm{X}}=\quad 1 \times 10^{-5} \mathrm{~cm}^{2} \mathrm{~s}^{-1} \text { (estimated based on dif- } \\
& \text { fusion of } \mathrm{O}_{2} \text { in range of organic solvents; } \\
& \text { Smith et al., 2002; King et al., 2008) } \\
& D_{\mathrm{b}, \mathrm{Y}}=10^{-7}-10^{-10} \mathrm{~cm}^{2} \mathrm{~s}^{-1} \text { (compare Smith et } \\
& \text { al., 2003) } \\
& \omega_{\mathrm{X}}=\quad 3.6 \times 10^{4} \mathrm{~cm} \mathrm{~s}^{-1} \text { (Smith et al., 2002; } \\
& \text { Pöschl et al., 2001; Ammann and Pöschl, } \\
& \text { 2007; King et al., 2009) } \\
& H_{\mathrm{cp}, \mathrm{X}}=4.8 \times 10^{-4} \mathrm{~mol} \mathrm{~cm}^{-3} \mathrm{~atm}^{-1} \text { (Smith et al., } \\
& \text { 2002; Morris et al., 2002; King et al., 2008, } \\
& \text { 2009) } \\
& \alpha_{\mathrm{s}, 0, \mathrm{X}}=4.2 \times 10^{-4}(\mathrm{BC} 1) \text { and } 8.5 \times 10^{-4}(\mathrm{BC} 2) \\
& \text { (compare Pöschl et al., 2001; Ammann and } \\
& \text { Pöschl, 2007; Shiraiwa et al., 2009) } \\
& k_{\mathrm{d}, \mathrm{X}}=\quad 100 \mathrm{~s}^{-1} \quad(\mathrm{BC} 1) \text { and } 1000 \mathrm{~s}^{-1} \quad(\mathrm{BC} 2) \\
& \left(k_{\mathrm{d}, \mathrm{X}}=0.1-10^{2} \mathrm{~s}^{-1}\right. \text { for ozone; Shiraiwa et } \\
& \text { al., 2009) } \\
& k_{\mathrm{SLR}, \mathrm{X}, \mathrm{Y}}=6 \times 10^{-12} \mathrm{~cm}^{2} \mathrm{~s}^{-1} ; \text { compare } 7.3 \times 10^{-11}
\end{aligned}
$$

$$
\begin{aligned}
& {[\mathrm{X}]_{\mathrm{gs}}=\quad 6.95 \times 10^{13} \mathrm{~cm}^{-3} \text { corresponding to } 2.8 \mathrm{ppm}} \\
& \text { (Ziemann, 2005) } \\
& k_{\mathrm{b}, \mathrm{X}}=\quad k_{\mathrm{BR}, \mathrm{X}, \mathrm{Y}} \times[\mathrm{Y}] \text { with } k_{\mathrm{BR}, \mathrm{X}, \mathrm{Y}}=1.7 \times 10^{-15} \\
& \mathrm{~cm}^{3} \mathrm{~s}^{-1} \text { corresponding to a literature value } \\
& \text { of } 1 \times 10^{6} \mathrm{~L} \mathrm{~mol}^{-1} \mathrm{~s}^{-1} \text { (Razumovskii et al., } \\
& \text { 1972, Lisitsyn et al., } 2004 \text { and Titov et al., } \\
& 2005 \text {; used in } \mathrm{BC} 1 \text {; reduced to } 5 \times 10^{-17} \\
& \mathrm{~cm}^{3} \mathrm{~s}^{-1} \text { in BC2) and }[\mathrm{Y}]_{0}=1.21 \times 10^{21} \\
& \mathrm{~cm}^{-3} \text { corresponding to } 3.15 \mathrm{~mol} \mathrm{~L}^{-1} \text { (Zie- } \\
& \text { mann, 2005) } \\
& T=\quad 296 \mathrm{~K} \\
& k_{\mathrm{b}, \mathrm{s}, \mathrm{X}}=318 \mathrm{~cm} \mathrm{~s}^{-1} \\
& k_{\mathrm{b}, \mathrm{ss}, \mathrm{Y}}=1.6 \times 10^{-3} \mathrm{~cm} \mathrm{~s}^{-1} \\
& k_{\mathrm{ss}, \mathrm{b}, \mathrm{Y}}=1.99 \times 10^{4} \mathrm{~s}^{-1} \\
& k_{\mathrm{s}, \mathrm{b}, \mathrm{X}}=9.8 \times 10^{4} \mathrm{~s}^{-1}(\mathrm{BC} 1) \text { and } 4.85 \times 10^{5} \mathrm{~s}^{-1} \\
& \text { (BC2) } \\
& \sigma_{\mathrm{X}}=1.8 \times 10^{-15} \mathrm{~cm}^{2} \text { (Pöschl et al., 2001; } \\
& \text { Ammann and Pöschl, 2007) and thus } \\
& \delta_{\mathrm{X}}=0.4 \mathrm{~nm} \text { (compare computational study } \\
& \text { by Vieceli et al., 2004) }
\end{aligned}
$$

Acknowledgements. CP wishes to thank the Royal Society (grant VO080001), the Research Endowment Trust Fund (University of Reading) and the NERC (grant NE/G000883/1). UP and MS acknowledge support from the European integrated project on cloud climate and air quality interactions (No. 036833-2 EUCAARI), the Max Planck Graduate Centre (MPGC), and the Ministry of Education, Culture, Sports, Science and Technology Japan (MEXT).

The service charges for this open access publication have been covered by the Max Planck Society.

Edited by: M. Kulmala

\section{References}

Ammann, M., Pöschl, U., and Rudich, Y.: Effects of reversible adsorption and Langmuir-Hinshelwood surface reactions on gas uptake by atmospheric particles, Phys. Chem. Chem. Phys., 5, 351-356, 2003.

Ammann, M. and Pöschl, U.: Kinetic model framework for aerosol and cloud surface chemistry and gas-particle interactions - Part 2: Exemplary practical applications and numerical simulations, Atmos. Chem. Phys., 7, 6025-6045, 2007, http://www.atmos-chem-phys.net/7/6025/2007/.

Andreae, M. O., Rosenfeld, D., Artaxo, P., Costa, A. A., Frank, G. P., Longo, K. M., and Silva-Dias, M. A. F.: Smoking rain clouds over the Amazon, Science, 303, 1337-1342, 2004.

Andreae, M. O. and Rosenfeld, D.: Aerosol-cloudprecipitation interactions. Part 1. The nature and sources of cloud-active aerosols, Earth-Sci. Rev., 89, 13-41, doi:10.1016/j.earscirev.2008.03.001, 2008. 
Atkins, P. W.: Physical Chemistry, Oxford University Press, 1998.

Bergstrom, R. W., Pilewskie, P., Russell, P. B., Redemann, J., Bond, T. C., Quinn, P. K., and Sierau, B.: Spectral absorption properties of atmospheric aerosols, Atmos. Chem. Phys., 7, 5937-5943, 2007 , http://www.atmos-chem-phys.net/7/5937/2007/.

Breon, F. M., Tanre, D., and Generoso, S.: Aerosol effect on cloud droplet size monitored from satellite, Science, 295, 834-838, 2002.

Charlson, R. J., Seinfeld, J. H., Nenes, A., Kulmala, M., Laaksonen, A., and Facchini, M. C.: Atmospheric science - Reshaping the theory of cloud formation, Science, 292, 2025-2026, 2001.

Choularton, T. W., Bower, K. N., Weingartner, E., Crawford, I., Coe, H., Gallagher, M. W., Flynn, M., Crosier, J., Connolly, P., Targino, A., Alfarra, M. R., Baltensperger, U., Sjogren, S., Verheggen, B., Cozic, J., and Gysel, M.: The influence of small aerosol particles on the properties of water and ice clouds, Faraday Discuss., 137, 205-222, 2008.

Fuzzi, S., Andreae, M. O., Huebert, B. J., Kulmala, M., Bond, T. C., Boy, M., Doherty, S. J., Guenther, A., Kanakidou, M., Kawamura, K., Kerminen, V.-M., Lohmann, U., Russell, L. M., and Pöschl, U.: Critical assessment of the current state of scientific knowledge, terminology, and research needs concerning the role of organic aerosols in the atmosphere, climate, and global change, Atmos. Chem. Phys., 6, 2017-2038, 2006, http://www.atmos-chem-phys.net/6/2017/2006/.

Gonzalez-Labrada, E., Schmidt, R., and DeWolf, C. E.: Kinetic analysis of the ozone processing of an unsaturated organic monolayer as a model of an aerosol surface, Phys. Chem. Chem. Phys., 9, 5814-5821, 2007.

Grimm, R. L., Hodyss, R., and Beauchamp, J. L.: Probing interfacial chemistry of single droplets with field-induced droplet ionization mass spectrometry: Physical adsorption of polycyclic aromatic hydrocarbons and ozonolysis of oleic acid and related compounds, Anal. Chem., 78, 3800-3806, 2006.

Gross, S., Iannone, R., Xiao, S., and Bertram, A. K.: Reactive uptake studies of $\mathrm{NO}_{3}$ and $\mathrm{N}_{2} \mathrm{O}_{5}$ on alkenoic acid, alkanoate, and polyalcohol substrates to probe nighttime aerosol chemistry, Phys. Chem. Chem. Phys., 11, 7792-7803, 2009.

Hearn, J. D. and Smith, G. D.: Kinetics and product studies for ozonolysis reactions of organic particles using aerosol CIMS, J. Phys. Chem. A, 108, 10019-10029, 2004.

Hearn, J. D., Lovett, A. J., and Smith, G. D:; Ozonolysis of oleic acid particles: evidence for a surface reaction and secondary reactions involving Criegee intermediates, Phys. Chem. Chem. Phys., 7, 501-511, 2005.

Hearn, J. D. and Smith, G. A.: Ozonolysis of mixed oleic acid/n-docosane particles: The roles of phase, morphology, and metastable states, J. Phys. Chem. A, 111, 11059-11065, 2007.

Hung, H. M. and Ariya, P.: Oxidation of oleic acid and oleic acid/sodium chloride(aq) mixture droplets with ozone: Changes of hygroscopicity and role of secondary reactions, J. Phys. Chem. A, 111, 620-632, 2007.

Iwahashi, M., Yamaguchi, Y., Kato, T., Horiuchi, T., Sakurai, I., and Suzuki, M.: Temperature-dependence of molecular conformation and liquid structure of cis-9-octadecanoic acid, J. Phys. Chem., 95, 445-451, 1991.

Katrib, Y., Biskos, G., Buseck, P. R., Davidovits, P., Jayne, J. T., Mochida, M., Wise, M. E., Worsnop, D. R., and Martin, S.
T.: Ozonolysis of mixed oleic-acid/stearic-acid particles: Reaction kinetics and chemical morphology, J. Phys. Chem. A, 109, 10910-10919, 2005.

King, M. D., Canosa-Mas, C. E., and Wayne, R. P.: Frontier molecular orbital correlations for predicting rate constants between alkenes and the tropospheric oxidants $\mathrm{NO}_{3}, \mathrm{OH}$ and $\mathrm{O}_{3}$, Phys. Chem. Chem. Phys., 1, 2231-2238, 1999.

King, M. D., Thompson, K. C., Ward, A. D., Pfrang, C., and Hughes, B. R.: Oxidation of biogenic and water-soluble compounds in aqueous and organic aerosol droplets by ozone: a kinetic and product analysis approach using laser Raman tweezers, Faraday Discuss., 137, 173-192, 2008.

King, M. D., Rennie, A. R., Thompson, K. C., Fisher, F. N., Dong, C. C., Thomas, R. K., Pfrang, C., and Hughes, A. V.: Oxidation of oleic acid at the air-water interface and its potential effects on cloud critical supersaturations, Phys. Chem. Chem. Phys., 11, 7699-7707, 2009.

King, M. D., Rennie, A. R., Pfrang, C., Hughes, A. V., Thomas, R. K., Dong, C. C., and Thompson, K. C.: Interaction of nitrogen oxide with a monolayer of oleic acid at the air-water interface: a simple proxy for atmospheric aerosol, Atmos. Environ., 44, 1822-1825, 2010.

Knopf, D. A., Anthony, L. M., and Bertram, A. K.: Reactive uptake of $\mathrm{O}_{3}$ by multicomponent and multiphase mixtures containing oleic acid, J. Phys. Chem. A, 109, 5579-5589, 2005.

Last, D. J., Najera, J. J., Percival, C. J., and Horn, A. B.: A comparison of infrared spectroscopic methods for the study of heterogeneous reactions occurring on atmospheric aerosol proxies, Phys. Chem. Chem. Phys., 11, 8214-8225, 2009.

Lee, A. K. Y. and Chan, C. K.: Single particle Raman spectroscopy for investigating atmospheric heterogeneous reactions of organic aerosols, Atmos. Environ., 41, 4611-4621, 2007.

Lisitsyn, D. M., Razumovskii, S. D., Tishenin, M. A., and Titov, V. N.: Kinetic parameters of oxidation of individual fatty acids with ozone, Bull. Exp. Biol. Med., 138, 457-459, 2004.

Moise, T. and Rudich, Y.: Reactive uptake of ozone by proxies for organic aerosols: Surface versus bulk processes, J. Geophys. Res.-Atmos., 105, 14667-14676, 2000.

Moise, T. and Rudich, Y.: Reactive uptake of ozone by aerosolassociated unsaturated fatty acids: Kinetics, mechanism, and products, J. Phys. Chem. A, 106, 6469-6476, 2002.

Morris, J. W., Davidovits, P., Jayne, J. T., Jimenez, J. L., Shi, Q., Kolb, C. E., Worsnop, D. R., Barney, W. S., and Cass, G.: Kinetics of submicron oleic acid aerosols with ozone: a novel aerosol mass spectrometric technique, Geophys. Res. Lett., 29, 1357, doi:10.1029/2002GL014692, 2002.

McNeill, V. F., Wolfe G. M., and Thornton, J. A.: The Oxidation of Oleate in Submicron Aqueous Salt Aerosols: Evidence of a Surface Process, J. Phys. Chem. A, 111, 1073-1083, 2007.

McNeill, V. F., Yatavelli, R. L. N., Thornton, J. A., Stipe, C. B., and Landgrebe, O.: Heterogeneous $\mathrm{OH}$ oxidation of palmitic acid in single component and internally mixed aerosol particles: vaporization and the role of particle phase, Atmos. Chem. Phys., 8, 5465-5476, 2008, http://www.atmos-chem-phys.net/8/5465/2008/.

Penner, J. E., Dong, X. Q., and Chen, Y.: Observational evidence of a change in radiative forcing due to the indirect aerosol effect, Nature, 427, 231-234, 2004. 
Pfrang, C., King, M. D., Canosa-Mas, C. E., and Wayne, R. P.: Correlations for gas-phase reactions of $\mathrm{NO}_{3}, \mathrm{OH}$ and $\mathrm{O}_{3}$ with alkenes: An update, Atmos. Environ., 40, 1170-1179, 2006a.

Pfrang, C., King, M. D., Canosa-Mas, C. E., and Wayne, R. P.: Structure-activity relations (SARs) for gas-phase reactions of $\mathrm{NO}_{3}, \mathrm{OH}$ and $\mathrm{O}_{3}$ with alkenes: An update, Atmos. Environ., 40, 1180-1186, 2006b.

Pfrang, C., King, M. D., Canosa-Mas, C. E., Flugge, M., and Wayne, R. P.: Gas-phase rate coefficients for the reactions of $\mathrm{NO}_{3}, \mathrm{OH}$ and $\mathrm{O}_{3}$ with $\alpha, \beta$-unsaturated esters and ketones: structure-activity relations (SARs), Atmos. Environ., 41, 17921802, 2007.

Pfrang, C., King, M. D., Braeckevelt, M., Canosa-Mas, C. E., and Wayne, R. P.: Gas-phase rate coefficients for reactions of $\mathrm{NO}_{3}$, $\mathrm{OH}, \mathrm{O}_{3}$ and $\mathrm{O}\left({ }^{3} \mathrm{P}\right)$ with unsaturated alcohols and ethers: Correlations and structure-activity relations (SARs), Atmos. Environ., 42, 3018-3034, 2008.

Pfrang, C., King, M. D., Lucas, C. O. M., Rennie, A. R., Hoare, I. D., Brown, G. D., and Campbell, R. A.: Establishing the fate of organic films on atmospheric aerosol: the reaction of ozone with a monolayer of d-methyl oleate studied by fast neutron reflectometry, in preparation, 2010.

Pöschl, U., Letzel, T., Schauer, C., and Niessner, R.: Interaction of ozone and water vapor with spark discharge soot aerosol particles coated with benzo[a]pyrene: $\mathrm{O}_{3}$ and $\mathrm{H}_{2} \mathrm{O}$ adsorption, benzo[a]pyrene degradation, and atmospheric implications, J. Phys. Chem. A, 105, 4029-4041, 2001.

Pöschl, U.: Atmospheric aerosols: Composition, transformation, climate and health effects, Angew. Chem.-Int. Edit., 44, 75207540, 2005.

Pöschl, U., Rudich, Y., and Ammann, M.: Kinetic model framework for aerosol and cloud surface chemistry and gas-particle interactions - Part 1: General equations, parameters, and terminology, Atmos. Chem. Phys., 7, 5989-6023, 2007,

http://www.atmos-chem-phys.net/7/5989/2007/.

Ramanathan, V., Crutzen, P. J., Kiehl, J. T., and Rosenfeld, D.: Atmosphere - Aerosols, climate, and the hydrological cycle, Science, 294, 2119-2124, 2001.

Razumovskii, S. D. and Zaikov, G. E.: Bull. Acad. Sci. USSR Div. Geologic, 616-620, 1971.

Reynolds, J. C., Last, D. J., McGillen, M., Nijs, A., Horn, A. B., Percival, C., Carpenter, L. J., and Lewis, A. C.: Structural analysis of oligomeric molecules formed from the reaction products of oleic acid ozonolysis, Environ. Sci. Technol., 40, 6674-6681, 2006.

Rosen, E. P., Garland, E. R., and Baer, T.: Ozonolysis of Oleic Acid Adsorbed to Polar and Nonpolar Aerosol Particles, J. Phys. Chem. A, 112, 10315-10324, 2008.

Rosenfeld, D.: Suppression of rain and snow by urban and industrial air pollution, Science, 287, 1793-1796, 2000.

Rudich, Y., Donahue, N. M., and Mentel, T. F.: Aging of organic aerosol: Bridging the gap between laboratory and field studies, Annu. Rev. Phys. Chem., 58, 321-352, 2007.

Sage, A. M., Weitkamp, E. A., Robinson, A. L., and Donahue, N. M.: Reactivity of oleic acid in organic particles: changes in oxidant uptake and reaction stoichiometry with particle oxidation, Phys. Chem. Chem. Phys., 11, 7951-7962, 2009.

Shiraiwa, M., Garland, R. M., and Pöschl, U.: Kinetic double-layer model of aerosol surface chemistry and gas-particle interactions
(K2-SURF): Degradation of polycyclic aromatic hydrocarbons exposed to $\mathrm{O}_{3}, \mathrm{NO}_{2}, \mathrm{H}_{2} \mathrm{O}, \mathrm{OH}$ and $\mathrm{NO}_{3}$, Atmos. Chem. Phys., 9, 9571-9586, 2009,

http://www.atmos-chem-phys.net/9/9571/2009/.

Shiraiwa, M., Pfrang, C., and Pöschl, U.: Kinetic multi-layer model of aerosol surface and bulk chemistry (KM-SUB): the influence of interfacial transport and bulk diffusion on the oxidation of oleic acid by ozone, Atmos. Chem. Phys., 10, 3673-3691, 2010, http://www.atmos-chem-phys.net/10/3673/2010/.

Smith, G. D., Woods, E., DeForest, C. L., Baer, T., and Miller, R. E.: Reactive uptake of ozone by oleic acid aerosol particles: Application of single-particle mass spectrometry to heterogeneous reaction kinetics, J. Phys. Chem. A, 106, 8085-8095, 2002.

Smith, G. D., Woods, E., Baer, T., and Miller, R. E.: Aerosol uptake described by numerical solution of the diffusion - Reaction equations in the particle, J. Phys. Chem. A, 107, 9582-9587, 2003.

Springmann, M., Knopf, D. A., and Riemer, N.: Detailed heterogeneous chemistry in an urban plume box model: reversible co-adsorption of $\mathrm{O}_{3}, \mathrm{NO}_{2}$, and $\mathrm{H}_{2} \mathrm{O}$ on soot coated with benzo[a]pyrene, Atmos. Chem. Phys., 9, 7461-7479, 2009, http://www.atmos-chem-phys.net/9/7461/2009/.

Thornberry, T. and Abbatt, J. P. D.: Heterogeneous reaction of ozone with liquid unsaturated fatty acids: detailed kinetics and gas-phase product studies, Phys. Chem. Chem. Phys., 6, 84-93, 2004.

Titov, V. N., Konovalova, G. G., Lisitsyn, D. M., Razumovskii, S. D., Nezhdanova, I. B., and Kukharchuk, V. V.: Kinetics of fatty acid oxidation in low density lipoproteins evaluated by registration of the oxidizer consumption and reaction product yield, Bull. Exp. Biol. Med., 140, 38-40, 2005.

Vesna, O., Kalberer, M., and Ammann, M.: Formation of hydrogen peroxide in the ozonolysis of mixed oleic acid $-\mathrm{NaCl}$ aerosol particles under humid conditions. Abstracts of Papers, 235th ACS National Meeting, New Orleans, LA, United States, 6-10 April, 2008a.

Vesna, O., Sjogren, S., Weingartner, E., Samburova, V., Kalberer, M., Gäggeler, H. W., and Ammann, M.: Changes of fatty acid aerosol hygroscopicity induced by ozonolysis under humid conditions, Atmos. Chem. Phys., 8, 4683-4690, 2008b, http://www.atmos-chem-phys.net/8/4683/2008/.

Vesna, O., Sax, M., Kalberer, M., Gaschen, A., Ammann, M.: Product study of oleic acid ozonolysis as function of humidity, Atmos. Environ., 43, 3662-3669, 2009.

Vieceli, J., Ma, O. L., and Tobias, D. J.: Uptake and Collision Dynamics of Gas Phase Ozone at Unsaturated Organic Interfaces, J. Phys. Chem. A, 108, 5806-5814, 2004.

Vieceli, J., Roeselova, M., Potter, N., Dang, L. X., Garrett, B. C., and Tobias, D. J.: Molecular dynamics simulations of atmospheric oxidants at the air-water interface: Solvation and accommodation of $\mathrm{OH}$ and $\mathrm{O}_{3}$, J. Phys. Chem. B, 109, 15876-15892, 2005.

Voss, L. F., Bazerbashi, M. F., Beekman, C. P., Hadad, C. M., and Allen, H. C.: Oxidation of oleic acid at air/liquid interfaces, J. Geophys. Res.-Atmos., 112(D6), D06209/1-D06209/9, doi:10.1029/2006JD007677, 2007.

Wayne, R. P.: Chemistry of Atmospheres, third ed., Oxford University Press, Oxford, 2000.

Worsnop, D. R., Morris, J. W., Shi, Q., Davidovits, P., and Kolb., C. E.: A chemical kinetic model for reactive transfor- 
mations of aerosol particles, Geophys. Res. Lett., 29, 1996, doi:10.1029/2002GL015542, 2002.

Zahardis, J. and Petrucci, G. A.: The oleic acid-ozone heterogeneous reaction system: products, kinetics, secondary chemistry, and atmospheric implications of a model system - a review, Atmos. Chem. Phys., 7, 1237-1274, 2007, http://www.atmoschem-phys.net/7/1237/2007/.
Ziemann, P. J.: Aerosol products, mechanisms, and kinetics of heterogeneous reactions of ozone with oleic acid in pure and mixed particles, Faraday Discuss., 130, 469-490, 2005. 